\title{
Anisotropic Storage Medium Development in a Full-Scale, Sodium Alanate-Based, Hydrogen Storage System
}

Scott W. Jorgensen a, Terry A. Johnson b, E. Andrew Payzant $c$, and Hassina Z. Bilheux ${ }_{c}$

a General Motors R\&D MC 480-102-000, 30500 Mound Road, Warren, MI 48092-2031, USA, scott.w.jorgensen@gm.com, b Sandia National Laboratory Thermal/Fluids Science and Engineering, 7011 East Avenue, Livermore, CA 94551, USA, tajohns@sandia.gov, c Oak Ridge National Laboratory 1 Bethel Valley Road, Bldg. 8600, Room B-438, Mailstop 6475, Oak Ridge, TN 37831-6475, USA, payzanta@ornl.gov, bilheuxhn@ornl.gov

Corresponding author: Scott Jorgensen: (586) 986-1915, scott.w.jorgensen@gm.com Scott Jorgensen

GM R\&D Labs, CMS lab, 480-102-000 30500 Mound Road

Warren, MI 48092-2031 USA 


\section{ABSTRACT}

Deuterium desorption in an automotive-scale hydrogen storage tube was studied in-situ using neutron diffraction. Gradients in the concentration of the various alanate phases were observed along the length of the tube but no significant radial anisotropy was present. In addition, neutron radiography and computed tomography showed large scale cracks and density fluctuations, confirming the presence of these structures in an undisturbed storage system. These results demonstrate that large scale storage structures are not uniform even after many absorption/desorption cycles and that movement of gaseous hydrogen cannot be properly modeled by a simple porous bed model. Furthermore, the evidence indicates that there is slow transformation of species at one end of the tube indicating loss of catalyst functionality. These observations explain the unusually fast movement of hydrogen in a full scale system and shows that loss of capacity is not occurring uniformly in this type of hydrogen-storage system.

Key Words: Sodium alanate, neutron diffraction, neutron computed tomography, hydrogen storage, vehicle scale, catalyzed desorption 


\section{Introduction:}

World yearly energy consumption is predicted to increase by 150 quadrillion BTUs between 2007 and 2020 [1]. There is no sign that this trend will abate, despite economic and political instabilities in several areas of the world. Accordingly, the pressure on existing energy resources will increase, and the need to diversify energy sources will grow [2]. The recent, highly successful combination of directional drilling with hydraulic fracturing commonly known as 'fracking' has changed the US from the biggest importer of petroleum products to the biggest producer, and this effective technique will no doubt be used internationally as regulation, technological expertise and political stability allow; yet even this new oil and gas resource base will not satisfy energy demands exclusively for more than a few years. Extensive use of conventional and alternative energy is highly likely as the world population and energy consumption per capita increase simultaneously. Use of biomass, solar, wind and other renewable resources requires conversion of the primary sources such as sunshine and switchgrass to more portable and versatile forms such as electricity, liquid fuels, or compressed gaseous fuel.

Hydrogen and fuel cells are an attractive option to carry energy from a diverse set of primary sources to end users for producing power in many applications, including transportation [3]. Significant progress has been made in the cost and durability of fuel cells for transportation [4], and while current methods such as compressed hydrogen tanks will serve for a hydrogen-fueled transportation system, improved density, specific mass, and system cost would enable faster market acceptance [5]. Accordingly, there has been a great deal of research on alternate methods of hydrogen storage [ 6 and references there in] and significant progress has been made in several branches of science to increase the amount of hydrogen than can be stored in or on solids [7]. There is still work to be done before these advanced methods of hydrogen storage will compete with compressed gas on both a performance and a cost basis, so research continues, seeking opportunities for improvement in the scientific and engineering aspects of advanced hydrogen storage [8].

Engineering and design will have a major impact on the mass, volume, functionality and cost of the storage system. In many solid state storage systems the containment and control of the storage media more than doubles the mass of the system [9]. Volume and especially cost can be strongly affected as well. As an example, high alloy stainless steel is often used in hydrogen service and is frequently base priced at $\$ 4.4 / \mathrm{kg}$ to $\$ 6.6 / \mathrm{kg}$, even at very high volume [10]. High strength aluminum alloys are typically significantly more expensive. Current system designs use over $100 \mathrm{~kg}$ of structural metal for the tank, the heat transfer surfaces, and the supply tubing. Furthermore, it is not only the raw materials that have an impact on the system cost, the assembly cost is intimately linked to the design, which itself flows from the system requirements and storage media capabilities. Thus, engineering plays a critical role in exploiting a storage media's abilities, covering its deficiencies, and the same time containing costs. Just as there is still much to learn in developing storage media, so too there is much to learn in how to best engineer storage systems.

In 2004 General Motors (GM) teamed with Sandia National Laboratory (SNL) to begin the design, construction and testing of a storage system based on complex hydrides. At the time sodium alanate $\left(\mathrm{NaAlH}_{4}\right)$ was the most studied and most feasible material to use, so they chose to use $\mathrm{NaAlH}_{4}$ as 
the storage media in the largest complex-hydride-based hydrogen-storage tank yet made [11]. Testing of this storage system using simulated automotive test cycles showed that it worked as designed in all important regards, yet there were subtle deviations from expected behavior. One aspect of especial engineering interest was the flow within the meter long tubes of modified $\mathrm{NaAlH}_{4}$ [12]. There were indications in the test data that the porous media flow equations were not capturing all aspects of hydrogen mass transport completely. As is discussed in [12], a modification to the model to include wall channeling (where hydrogen flows preferentially adjacent to the wall of the vessel due to greater permeability near the wall) provided a better match to experimental data. While it was conceivable that this theory explained the discrepancy in hydrogen flow, it had not been confirmed. The models described in [12] were indispensable in developing the hydrogen storage system, and any future system or subsystem design would be much improved if the correct flow could be modeled with confidence. As mass and heat transfer are intimately linked in this system design, the changes in mass movement will affect heat flows both locally and, to a lesser extent, overall. Understanding the true nature of gas flow in a full scale system would help in design refinements and could also improve the design of other types of solid-phase hydrogen storage systems. Destructive investigation of a storage tube indicated that a number of sub-structures had developed in the packed storage material, including cracks, macroscopic tunnels or "wormholes" and in places a narrow gap between wall and storage media (see Figure 1); however, it was not readily possible to determine to what extent these observed changes were due to the process of cutting open the stainless steel tubes and removing the packed media.

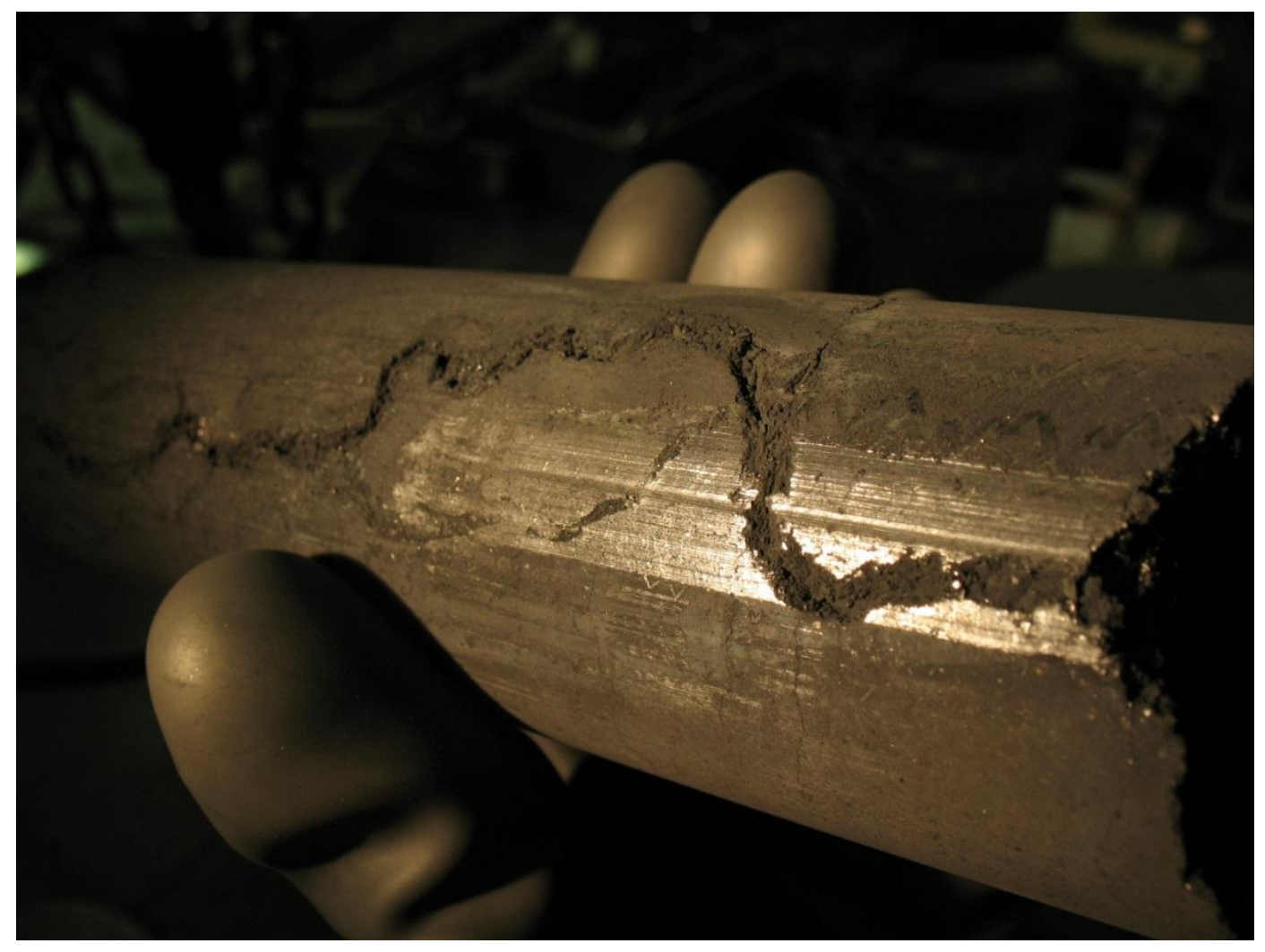

Figure 1: Hydrogen storage media after many cycles and subsequent removal from its tube. Note the furrows or "wormholes" along the surface, and both large and fine cracks. 
During the course of testing and operating the tank there was degradation of the capacity. This is not a unique finding, but capacity loss must be minimized in any commercial system. This is the first time this much sodium alanate was subjected to the high demands of simulated automotive use. It was observed that the capacity loss was greater than observed in small lab samples. We wanted to understand the reason for this capacity loss and also wanted to understand if it was uniform or if it was spatially inhomogeneous.

Physical inspection inherently cannot provide information on the dynamics of hydrogen movement in various states of fill. In-situ investigation by non-invasive means would be very valuable in determining if the engineering assumptions used to design the GM/SNL system held after extensive cycling. With several complex hydride tank efforts being made internationally, it would be valuable to better understand mass flows in this system so that better engineering designs might be formulated to take advantage of opportunities or ameliorate deficiencies in future efforts [see references 6 and 8 ].

Neutrons offer a non-invasive method of studying internal structures of some engineered materials. In general, facilities are available for gram size samples, while in very few locations is a high flux neutron beam available with a stage to accommodate moderate size samples or parts. Fortunately, the number of locations with this capability is increasing. In 2010 the Spallation Neutron Source (SNS), activated the Vulcan beam line, a facility specifically designed to accommodate parts up to a few meters in length. A very bright, time of flight, neutron beam is delivered above a stage designed for highly precise positioning of parts with 4 dimensional ( $X, Y, Z$, and theta) control. This arrangement was precisely what was needed to investigate the internal state of the GM/SNL storage tubes.

Our use of neutrons to study hydrogen storage systems is not unique [13-17]. A neutron radiography and computed tomography study was conducted at NIST using the BT2 Neutron Imaging Facility. This very productive beam line was upgraded to make measurements of water in fuel cells but is also suited to radiography of other moderate size structures. A team from Jet Propulsion Labs, the Univ. of Maryland, Oak Ridge National Laboratory (ORNL), and NIST used it to study hydrogen in the compressor element of the Planck Sorption Cryo-cooler, a $31.5 \mathrm{~mm}$ (OD) stainless steel tube just over 36 $\mathrm{cm}$ long containing aluminum foam packed with LaNi4.78Sn0.22 storage media, with a $6.6 \mathrm{~mm}$ diameter porous tube at its center [15]. A series of radiographs show the progress of hydrogen through the bed. Since the media forms a solution hydride, the simple absorption and scattering of neutrons serves as a good measure of hydrogen content. Similarly, two teams led by members of the Helmholtz-Zentrum Geesthacht, Centre for Materials and Coastal Research have use both radiography and small angle neutron scattering (SANS)/ultra-small angle neutron scattering (USANS) to understand the behavior of sodium alanate $[\mathbf{1 6}, \mathbf{1 7}]$. Significant morphology changes are observed in these specially built test articles.

Our intent was somewhat different. In addition to morphology we wished to also apprise the chemical state. Under the conditions we used in testing the system, sodium alanate passes through 3 distinct chemical phases. The hydrogen saturated phase $\mathrm{NaAlH}_{4}$ will desorb hydrogen when heated and leave aluminum metal and $\mathrm{Na}_{3} \mathrm{AlH}_{6}$, which at yet higher temperature desorbs more hydrogen to yield more aluminum metal and the final phase accessible at moderate temperatures, $\mathrm{NaH}$. Stoichiometry requires that the first transformation release $2 / 3$ of the hydrogen stored and second step releases the last $1 / 3$ of the hydrogen. A titanium catalyst allows this system to operate at temperatures below 
$200{ }^{\circ} \mathrm{C}[18, \mathbf{1 9}]$. The mechanism has been widely debated but recent work favors vacancy moderated mobility of species in the more hydrogen rich phases $[\mathbf{2 0}, \mathbf{2 1}]$.

To understand the chemical state spatially, we needed to determine not only increasing or decreasing amounts of hydrogen but also which of three possible storage phases the hydrogen was in. Radiography and computed tomography provide us with the large scale structure, such as cavities and worm holes, but neutron diffraction at several points is required to begin to map out the extent of hydrogen reaction as a function of position and the system's state of fill. Doing this in a reasonable amount of time inside a three millimeter thick stainless steel tube required a scanning capability with a bright beam that could accommodate and rapidly, reproducibly, manipulate a fairly large object. The Vulcan line at SNS provided all of these capabilities.

\section{Experimental set-up:}

Briefly, the GM/SNL storage system consists of four identical modules. Each storage module is a shell and tube heat exchanger with sodium alanate stored inside the tubes and heat transfer fluid flowing inside the shell. The module design was the result of extensive, experimentally validated, computational simulations [22]. Twelve tubes arranged in a staggered 4 by 3 array make up each module. The tubes are constructed from $316 \mathrm{~L}$ stainless steel, $5.7 \mathrm{~cm}\left(2.25^{\prime \prime}\right)$ in outer diameter and $\sim 91$ $\mathrm{cm}\left(36^{\prime \prime}\right)$ long (Figure 2). The tubes were designed for a maximum normal working pressure of $13.8 \mathrm{MPa}$ (2000 psi) hydrogen. Each tube was filled with $1.79 \mathrm{~kg}$ of a sodium alanate - graphite mixture $(1 \mathrm{~g} / \mathrm{cc}$ packing density) so that each module contained about $21.5 \mathrm{~kg}$ of material. The storage media was created in an $\mathrm{Ar}$-filled glove box from $\mathrm{NaH}, \mathrm{Al}$, and $\mathrm{TiCl}_{3}$ which were ball milled in $125 \mathrm{~g}$ batches for four, 1-hour cycles using two Fritsch P5 mills. The batches were hand mixed with expanded natural graphite (ENG) to give the final media which when fully hydrogenated had the following mass proportions: $1.8 \%$ $\mathrm{Ti}, 6.8 \% \mathrm{NaCl}, 8.7 \% \mathrm{C}, 13.3 \% \mathrm{Al}$, and $69.3 \% \mathrm{NaAlH}_{4}$. The expected mass ratios in the $\mathrm{Na}_{3} \mathrm{AlH}_{6}$ state are: $1.9 \% \mathrm{Ti}, 6.9 \% \mathrm{NaCl}, 9.0 \% \mathrm{C}, 37.4 \% \mathrm{Al}$, and $44.8 \% \mathrm{Na}_{3} \mathrm{AlH}_{6}$ and in the $\mathrm{NaH}$ state are: $1.9 \% \mathrm{Ti}, 7.0 \% \mathrm{NaCl}$, $9.1 \% \mathrm{C}, 49.9 \% \mathrm{Al}$, and $32.0 \% \mathrm{NaH}$.
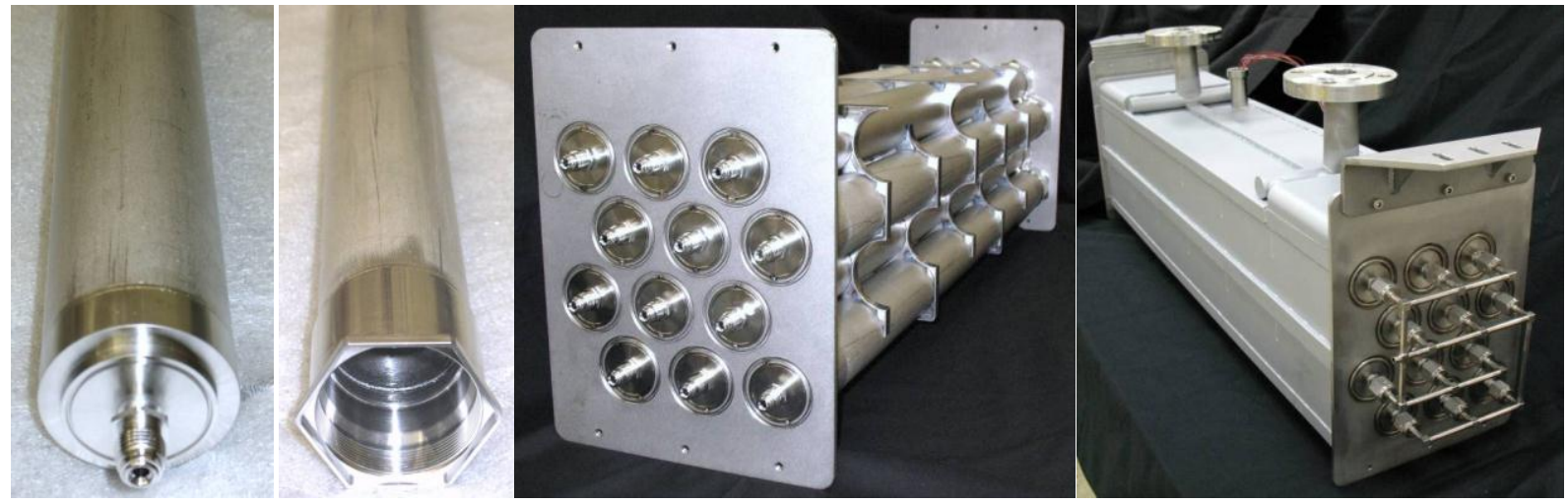

Figure 2. Details of a module tube (left) and a tube bank prior to shell attachment (right) 
The completed system was subjected to nearly a year of testing under a variety of simulated automotive cycles. The system and its performance are described completely in reference $\mathbf{1 1}$ and references there-in.

Module \#3 was removed from the Demonstration System after the $79^{\text {th }}$ cycle. The heat exchanger shell was removed from the module to separate out individual tubes for analysis. The module's shell was removed by systematically grinding off the welds holding the shell together. Next the module end plates were removed by a similar method. The twelve tubes were successfully separated from the assembly and transferred into a glove box for storage. They were then treated with $\mathrm{CO}_{2}$ to eliminate any unstable oxidation products that might have formed in a year of cycling. After the final $\mathrm{CO}_{2}$ treatment was complete, the tubes were transferred back to the glove box. In the inert environment, one of the tubes was cut into sections of 15 to $20 \mathrm{~cm}$ in length. The sodium alanate had sintered into solid cylinders over most of the length. These cylinders had shrunk away from the inner wall of the tubes so it was possible to remove them in individual pieces. The sodium alanate sections were then measured and catalogued. Pictures of a sectioned tube are shown below in Figure 3.
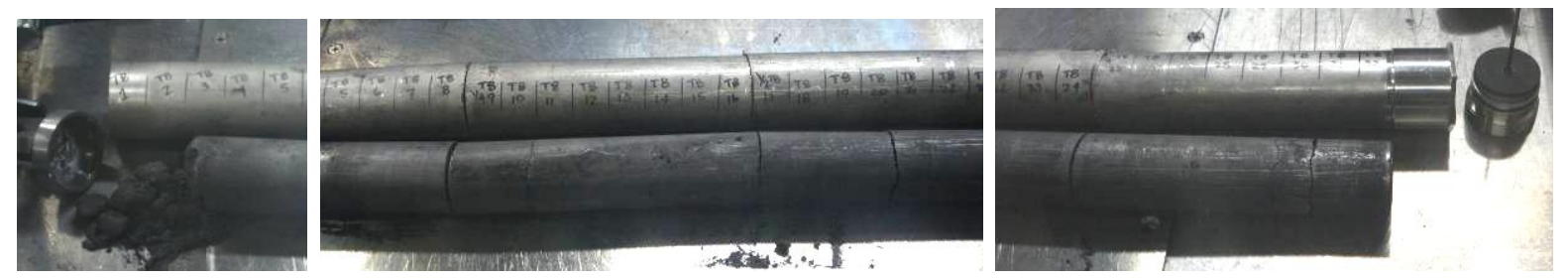

Figure 3. A sectioned tube from Module 3 with the sodium alanate removed.

Initially, three of the remaining eleven tubes were prepared for neutron diffraction scoping experiments to determine the feasibility of this work. The tubes were filled to different levels with hydrogen to determine if the different phases of sodium alanates could be resolved with neutron diffraction techniques. One tube was fully desorbed and was expected to contain only $\mathrm{NaH}, \mathrm{Al}$, and C. A second tube was partially filled such that the tube primarily contained the $\mathrm{Na}_{3} \mathrm{AlH}_{6}$ phase along with $\mathrm{Al}$ and C. Finally, the third tube was filled to its capacity. In this state we would expect both alanate phases, primarily $\mathrm{NaAlH}_{4}$ and a small amount of $\mathrm{Na}_{3} \mathrm{AlH}_{6}$, along with some $\mathrm{Al}$ and $\mathrm{C}$ since complete conversion to $\mathrm{NaAlH}_{4}$ is difficult to obtain. With these three tubes, scoping experiments were conducted at the High Flux Isotope Reactor (HFIR) at ORNL using the Wide Angle Neutron Diffractometer (WAND). The experimental results were promising in that we were able to resolve all phases $(\mathrm{C}, \mathrm{NaH}, \mathrm{NaCl}$, $\mathrm{Na}_{3} \mathrm{AlH}_{6}, \mathrm{NaAlH}_{4}$ and $\mathrm{Al}$ ) in the samples.

The HFIR experiments gave us confidence that the alanate phases could be individually resolved, even through the walls of the stainless steel vessels. However, this initial data was all collected on tubes containing natural hydrogen, with the knowledge that the high incoherent cross-section of hydrogen would yield low signal and high background compared to what could be accomplished with deuterated samples. In addition, the WAND is a high-flux diffractometer with a fast data collection system, but with fairly low angular resolution. These scoping experiments were performed in preparation for a more rigorous set of experiments to be conducted using the newly commissioned VULCAN beam line at 
ORNL's Spallation Neutron Source. To get the maximum signal to noise ratio in our experiments conducted at VULCAN, three new tubes were prepared using deuterium instead of hydrogen.

Three H-D exchange cycles were carried out with the three new tubes to achieve a high deuterium content. The tubes were cycled between the $\mathrm{NaH}$ phase and the $\mathrm{Na}_{3} \mathrm{AlH}_{6}$ phase which allowed for the maximum exchange with the least amount of deuterium used. Starting from the fully desorbed state $(\mathrm{NaH}, \mathrm{Al}$, and $\mathrm{C})$, the tubes were filled with $\mathrm{D}_{2}$ at a pressure of 600-700 psi and a temperature that ranged from $100{ }^{\circ} \mathrm{C}$ to $130{ }^{\circ} \mathrm{C}$. This combination of pressure and temperature ensured that the tetrahydride phase would not form. Following each absorption, the tubes were then heated to $\sim 200^{\circ} \mathrm{C}$ and fully desorbed. Assuming that there was no preference for $\mathrm{D}$ or $\mathrm{H}$ atoms to be released during desorption, the first cycle resulted in a 1:1 $\mathrm{D}$ to $\mathrm{H}$ ratio, the second cycle resulted in a 3:1 ratio, and the third cycle resulted in a 7:1 ratio.

Following the third desorption, one of the tubes was left in the fully desorbed state (aluminum and sodium hydride only). The second tube was then partially filled with deuterium such that primarily the hexahydride phase was present along with $\mathrm{Al}$ and $\mathrm{C}$. The estimated $\mathrm{D}$ to $\mathrm{H}$ ratio for this tube was then 15:1. The third tube was filled to 2/3 capacity by increasing the $D_{2}$ pressure to 2000 psi following the absorption to the hexahydride phase. This tube was expected to contain both alanate phases, $\mathrm{Na}_{3} \mathrm{AID}_{6}$ and $\mathrm{NaAID}_{4}$ as explained above. If completely filled to form only $\mathrm{NaAlD}_{4}$, this tube would have a $\mathrm{D}$ to $\mathrm{H}$ ratio of 23:1.

The three deuterated tubes were tested at ORNL's neutron facilities in three separate experiments. The first of these experiments included neutron diffraction measurements of all three tubes using the VULCAN beam line at SNS. These experiments included sets of data taken at locations along the length and along radial lines of the tubes. The second experiment was conducted with just one tube. The fully absorbed tube was interrogated again using the VULCAN instrument, however this time the tube was desorbed in steps using an ex-situ apparatus. Data was taken at locations along the length of the tube at each state of capacity. Four states were measured from nearly full to fully desorbed. Finally, this same tube, now in the fully desorbed state, was imaged using neutron radiography and computed tomography at HFIR. All of the above experiments will be described in more detail in the following sections.

The VULCAN facility offered the unique matching of a very bright neutron source with a test space well suited to investigating full sized engineered items. This combination of attributes allows for in-situ investigation of large items without compromise. A full suite of data gathering equipment with helpful, safety conscious, and knowledgeable staff support at VULCAN greatly enabled the challenging measurement of phase changes within a meter long, $5.7 \mathrm{~cm}$ stainless steel tube. SNS provides neutrons in packets at 20 to $60 \mathrm{~Hz}$ with a flux on sample of $2.2 \times 10^{7}$ to $6.7 \times 10^{7} \mathrm{n} /\left(\mathrm{s} \cdot \mathrm{cm}^{2}\right)$ depending on operating mode. We chose to operate at $30 \mathrm{~Hz}$ to provide us a d-spacing bandwidth from 0.5 to $2.8 \AA$.

The sample stage at VULCAN provides rotation and 3 dimensional translation. In both the $X$ and $\mathrm{Y}$ directions in the plane of the floor, translation from -250 to $+250 \mathrm{~mm}$ is possible and in the $Z$ direction 
translation from $-300 \mathrm{~mm}$ to $+300 \mathrm{~mm}$ is possible. Rotation is possible through a full 360 degrees. The precision of positioning is better than $25 \mu \mathrm{m}$ for loads such as ours that have a mass less than $200 \mathrm{~kg}$.

Several kinds of dedicated apparatuses are available to mount on the stage to perform specific tests. We assembled our own mount on site to orient our test item optimally (Figure 4). An aluminum support skeleton was assembled and fixed to the stage to provide easy access to the portions of the

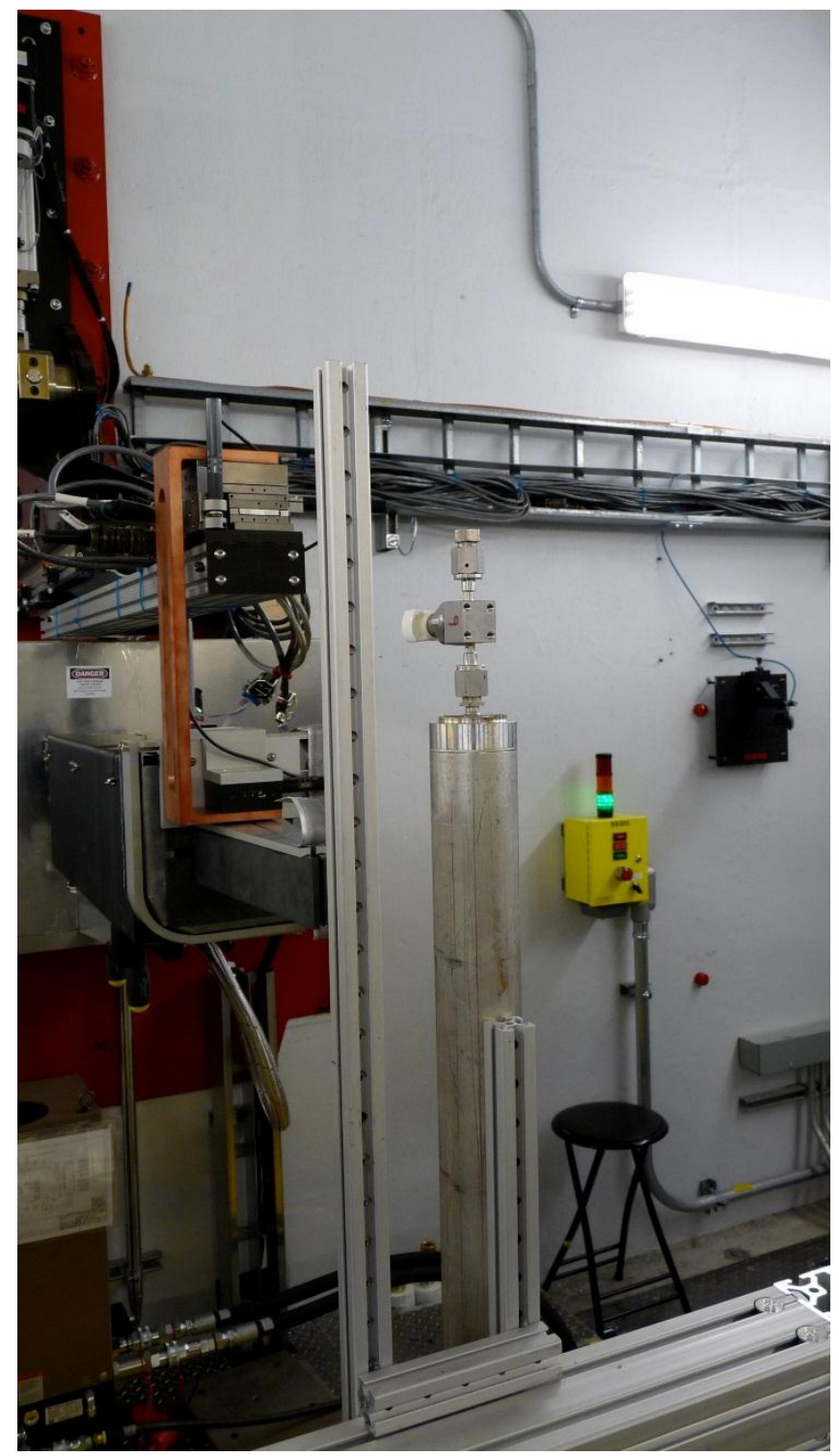

Figure 4: Aluminum structure (lower center of photo) holding the test article in the position for study of the top half of the tube. A second, taller, fixture-position (a few centimeters to the left in this picture) allowed spectra of the lower half of the tube to be taken. A reference stop not seen in this angle ensures the vertical position is exactly reproducible. The neutron beam comes from the direction of the orange ' $C$ ' shaped metal piece in the background, no aluminum shades the sample. 
tube we wished to sample with a minimum of physical handling. In addition, a camera may be trained on the sample to confirm positioning accuracy. A series of fiduciary marks allowed us to confirm the proper positioning of the test item. The error in positioning from test to test is 2 orders of magnitude less than the narrower dimensions of the gauge volume, meaning that effectively the exact same volume of the test article was sampled in repeated tests conducted at the same location in the test article.

As outlined above, an initial set of experiments on 3 tubes, each in a fixed state of fill, are reported here. These experiments were simpler than the single tube tests, but some ambiguity exists as to whether the changes observed arise from the different states of fill, or from tube-to-tube variation. In these tests each of the three tubes was sampled along its length at two angular positions and at both the surface of the media (next to the inside of the steel tube) and at the core of the sample. In addition, a series of data at increasing depth were obtained at the midpoint and the ends. In these experiments a larger spacing was chosen due to the beam time available and the number of diffraction measurements needed. Data was obtained at the midpoint and at $80 \mathrm{~mm}$ intervals in each direction as shown graphically in Figure 5. 


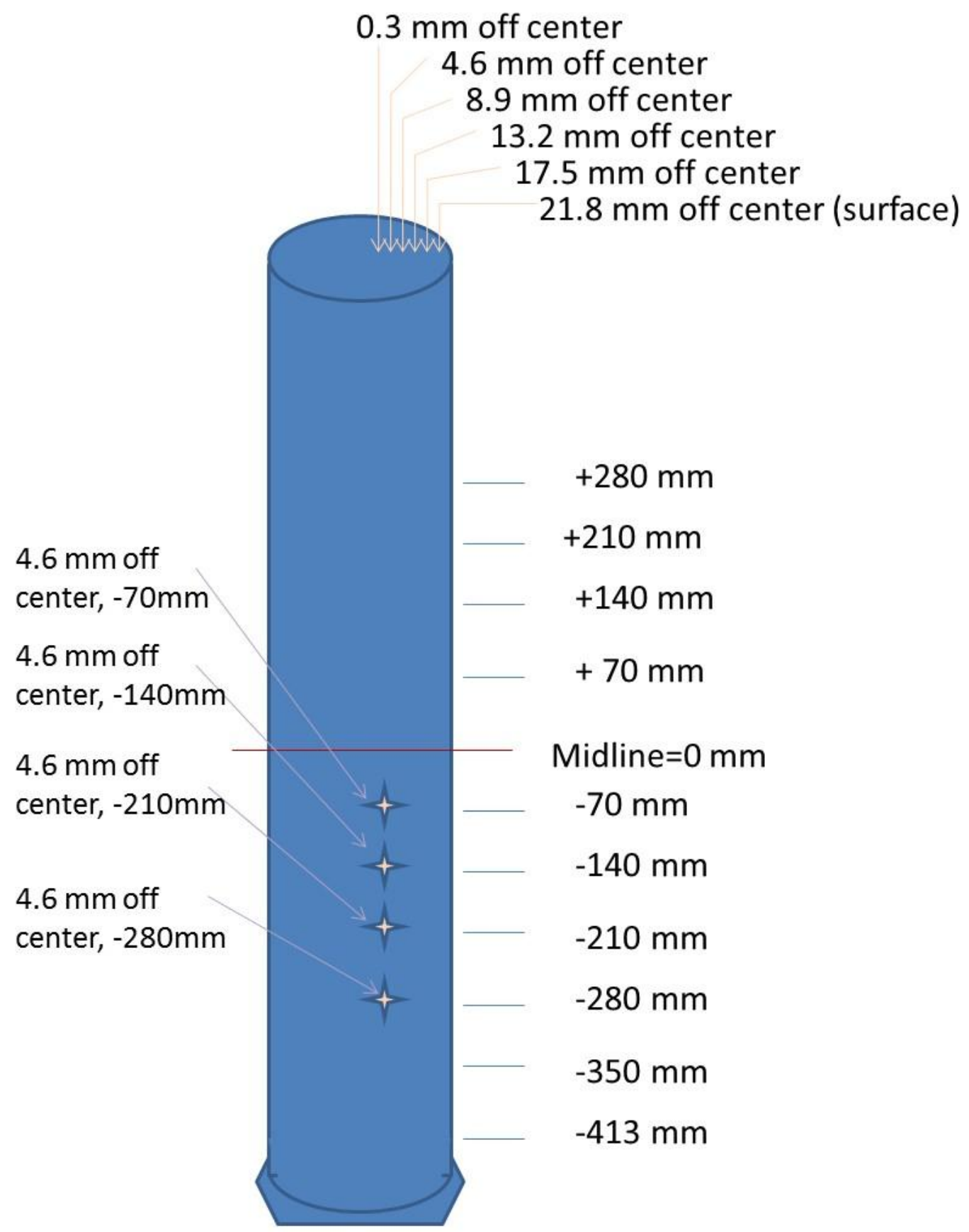

All points $45^{\circ}$ off beam line Unless marked

Figure 5: Location of sample points along the length and along the radial direction of the three hydrogen storage tubes used to obtain the initial data. The figure is illustrative and not to scale. A full set of points were taken along the right edge in this figure plus the four points indicated by stars that are also at the surface but in a rotated position. Radial depth data were taken at the midpoint and the ends at the positions indicated at the top of the figure. 
Data between the outer edge and the core was obtained at $4.3 \mathrm{~mm}$ intervals starting at the nominal surface position of $21.8 \mathrm{~mm}$ from the tube's long axis. The tubes were in states of fill expected to nominally be empty, entirely in the hexa-alanate phase, and in a state of fill where both hexa-alanate and tetra-alanate phases exist. These are comparable to the last, second and first sets of data in the single tube data set described below. These experiments were the first at the Vulcan site by an outside group, and at that time the gauge volume control was still being improved. For this set of experiments the gauge volume was approximately $20 \mathrm{~mm}$ high, $10 \mathrm{~mm}$ wide and $10 \mathrm{~mm}$ deep.

In order to more clearly understand the alanate phase distribution in the hydrogen storage vessels as a function of state of fill, a set of experiments was conducted using a single tube to eliminate the effects of tube-to-tube variations. Thus, the fullest tube, the one where both hexa-alanate and tetra-alanate phases existed, was used for these experiments. Ideally, we would have carried out neutron diffraction measurements during a desorption process conducted in the fixture holding the tube in the neutron beam. However, this quite complex scenario was not feasible for a number of reasons. Firstly, the time scale associated with obtaining quality measurements was much greater than that for desorbing hydrogen from the tube. Each test point was interrogated for at least $\mathbf{3 0}$ minutes to obtain a suitable signal to noise ratio, and 17 of these points were measured at each state of fill. In addition to the limited time available for these measurements, performing the desorption experiments inside the VULCAN test hutch while the beam was active would have required remote control of automated valves as well as remotely monitored temperature, pressure, and gas flow measurements. The VULCAN facility was not equipped for such a test, and resource and schedule constraints precluded assembly of such a system.

Instead, a desorption apparatus was assembled a few meters outside the test-hutch that allowed us to heat the tube to the desired temperature, manually control and measure the flow of the desorbing gas, and safely vent it outside of the VULCAN facility. The position of the tube in its rig was precisely marked, the tube was removed from the rig and brought to the desorption apparatus. After desorption and cooling the tube was replaced in the rig in the same location and angular orientation.

Figure 6 below shows a diagram of the desorption apparatus. The desorption procedure is listed in Table 1. As Figure 7 shows, the tube was wrapped with a tape-type resistive heater and then wrapped with $3 \mathrm{~cm}$ thick Kaowool insulation. Despite the insulation, uniform temperature was difficult to achieve due to the incomplete coverage of the tube by the heater. The effect of temperature uniformity will be discussed with respect to the alanate phase distributions in a later section. The desorption procedure listed in Table 1 was carried out 3 times to give a total of four states from mostly full to fully discharged. Neutron diffraction measurements were made at the same 17 points for each of the states and will be compared. Fiduciary marks, the sample table system, and a laser spatial reference allowed precise return to the same testing points. The error in reacquiring the same test points is estimated at under $0.1 \mathrm{~mm}$, an order of magnitude smaller than the gauge volume sampled. 


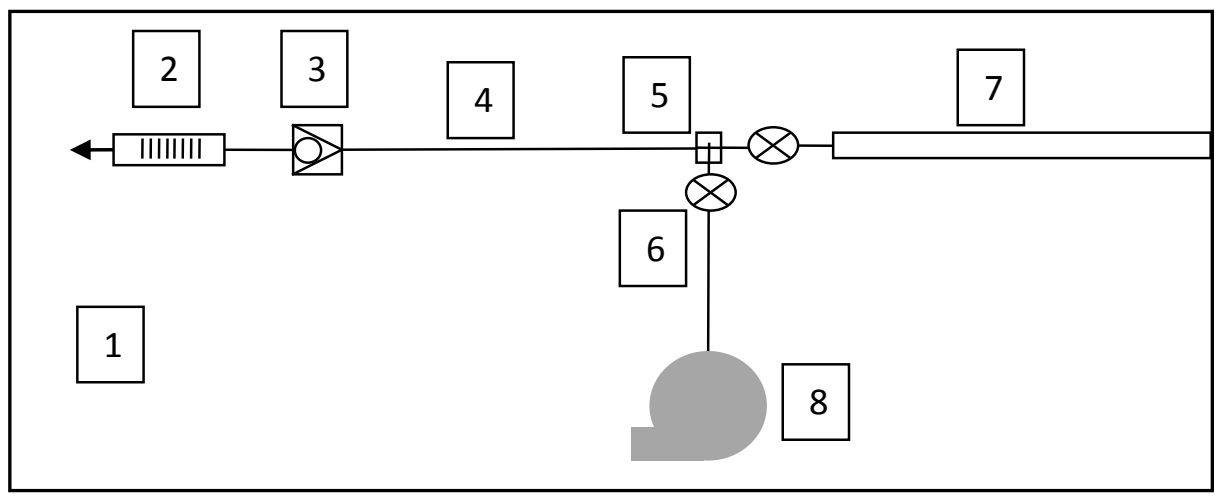

Figure 6 Schematic of the desorption system

1 fire extinguisher, 2) rotameter and exit to release hydrogen outdoors, 3) check valve to prevent flow reversal, 4) flexible tubing, 5) tee connection, 6) shut off valve, 7) Hydrogen storage tube wrapped in heating tape and insulation, 8) vacuum pump.

Table 1: Desorption process

1. Attach the alanate tube (7) to the tee (5) which is connected to the flexible tubing (4) and the manual valve (6) and the vacuum pump (8).

2. Attach a check valve (3) to the opposite end of the flex tube to prevent air back streaming

3. Attach an air flow rotameter (2) to the check valve (3) to measure the D2 flow rate.

4. Wrap the alanate tube (7) with heat tape and attach several thermocouples

5. Heat the alanate tube (7) to $\sim 160 \mathrm{C}$ to desorb the tet phase and $\sim 200 \mathrm{C}$ to desorb the hex phase.

6. Purge the flex tubing by opening the manual valve (6) to the vacuum pump (8) and evacuating the line. Then close the manual valve (6).

7. Slowly open the alanate tube valve (7) and monitor the rotameter (2). Try to keep a constant flow rate by adjusting the valve and the alanate tube temperature.

8. Time the flow of D2 and close the alanate tube valve (7) once the desired amount of D2 has been desorbed.

9. Cool the alanate tube (7) with a fan and/or wet cloth. Once cool, vent any overpressure to the flex line (4).

10. Once vented, close the alanate valve (7) and remove from the manifold for mounting on the Vulcan stage. 

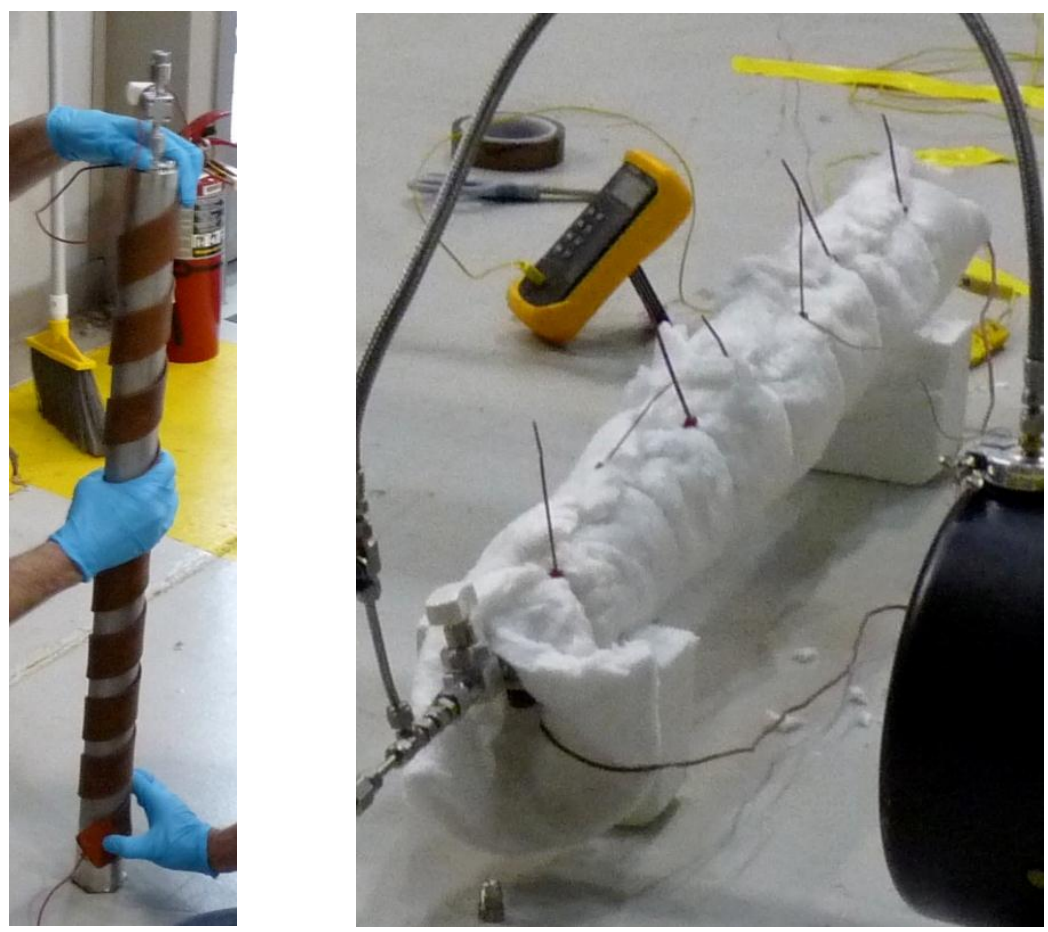

Figure 7: Heating tape being applied to the test article (left) and the finished heating arrangement with the article further wrapped in Kaowool insulation.

The single tube started at a fill state of about $65 \%$ of the accessible hydrogen, a state of fill which will require the presence of both the hexa-alanate and the tetra-alanate. This tube was mounted on the fixture shown in Figure 5 and diffraction data were obtained at locations spaced at $50 \mathrm{~mm}$ intervals from the middle of the tube to $400 \mathrm{~mm}$ toward the inlet fitting. Reference lines were marked on the outside of the tube so that we could precisely locate data sampling points inside the tube axially, radially and rotationally. Data were taken along a vertical line near the outside edge of the alanate bed. After these nine points were sampled, the tube was placed on a fixed, raised, step, and points at $50 \mathrm{~mm}$ intervals from the midline to $400 \mathrm{~mm}$ toward the closed end of the tube were sampled. The gauge volume in these tests was $20 \mathrm{~mm}$ high, $5 \mathrm{~mm}$ wide and $5 \mathrm{~mm}$ deep as depicted in Figure 8. For clarity, sample locations are graphically illustrated in Figure 9. As is clear in the spectra, no steel (iron) peaks are observed and the sampled volume is therefore entirely inside the storage media. We set the test to center on a depth $5 \mathrm{~mm}$ inside the wall of the tube. Comparison of replicate tests at the midline (one in the lower and one in the raised test positions) indicate that there was no variation between these tests, consistent with the same sample location being sampled in each orientation. 

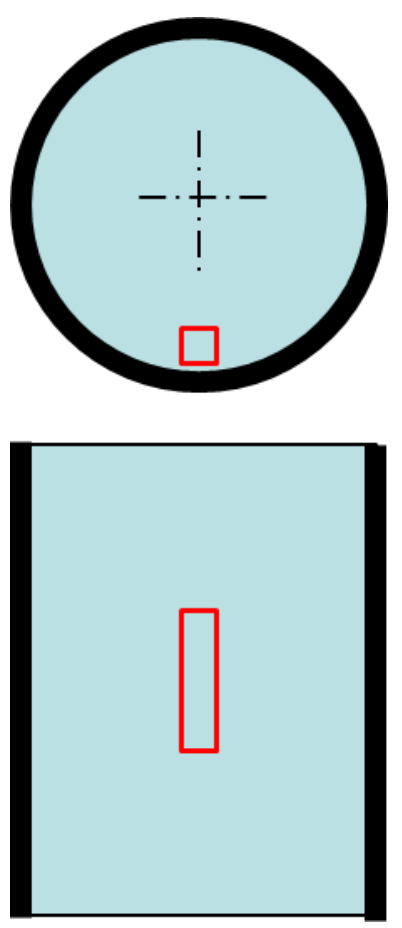

Figure 8. Down axis (top) and radial (bottom) views of the neutron beam gage volume in the hydrogen storage tube, the gage volume is set by the slits and detector to $5 \times 5 \times 20 \mathrm{~mm}$ 


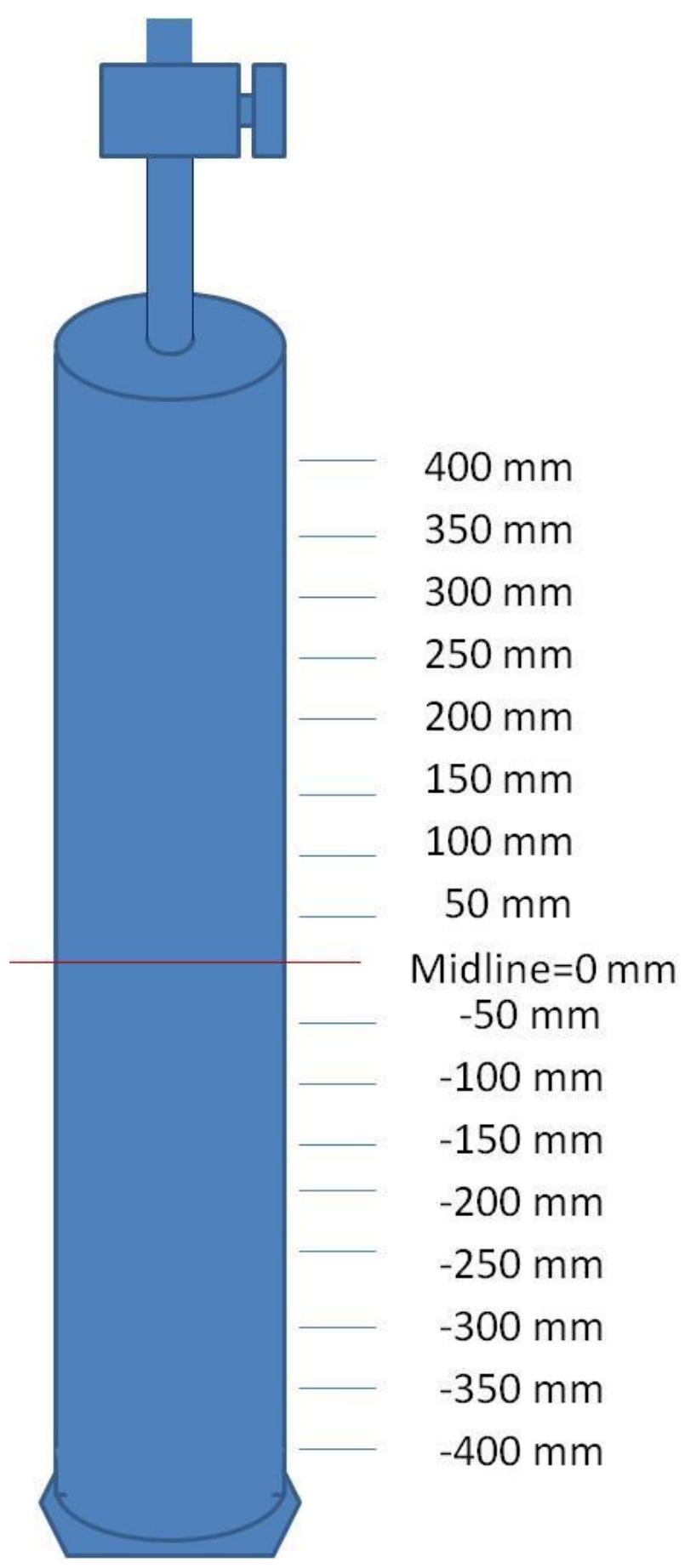

Figure 9: Location of sample points along the length of the hydrogen storage tube used to obtain the primary data. The figure is illustrative and not to scale.

After the first set of diffraction data was obtained, the tube was removed from the sample stage and deuterium was removed as described above. In preparation for the second set of diffraction data we attempted to eliminate the tetra-alanate phase but preserve the hexa-alanate phase by limiting the temperature in the storage media to $120^{\circ} \mathrm{C}$. Approximately $210 \mathrm{~L}$ or $34 \mathrm{~g}$ of $\mathrm{D}_{2}$ was desorbed. The tube 
was cooled from the outside with flowing air and returned to the stage for a second set of data collection at the same points along the tube. Upon completion of data collection the tube was again removed from the sample stage and approximately $125 \mathrm{~L}$ or $20 \mathrm{~g}$ of $\mathrm{D}_{2}$ were removed by heating to an internal temperature of $180^{\circ} \mathrm{C}$. This was expected to yield some hexa-alanate and some sodium hydride and more aluminum. The tube was again air cooled and returned to the sample stage where a third set of diffraction data was acquired at the same points along the tube. Finally the tube was removed for a final time, heated to an internal temperature of $210^{\circ} \mathrm{C}$ causing desorption of $89 \mathrm{~L}$ or approximately $14 \mathrm{~g}$ of deuterium. The expectation was that this should bring the tube to the functionally empty state; recall that while deuterium was still present in the form of sodium deuteride, it was not practically accessible in the intended use as a hydrogen storage system. The tube was cooled as above and remounted for a final set of data obtained at the same locations previously sampled. This last set of data will be referred to as the empty tube.

The raw data were refined using GSAS [23]. Reference spectra for each of the three alanate phases ( $\mathrm{NaD}, \mathrm{Na}_{3} \mathrm{AlD}_{6}$ \{monoclinic structure\}), and $\mathrm{NaAlD}_{4}$ ), $\mathrm{NaCl}, \mathrm{C}$ as graphite, and $\mathrm{Al}$ metal were used to fit the spectra. Iron was also available as a standard but was never detected. Refined variables included the background, lattice parameters, phase fraction, and scale factor. The refinement was started at a ratio of species roughly indicated by the degree of desorption.

Because it was impractical to fully deuterate this very large amount of alanate, there is a combination of $\mathrm{D}$ and $\mathrm{H}$ atoms in the sample, giving rise to multiple occupancies. When we ran the refinement allowing for multiple occupancies a significantly better fit was obtained. Since partially hydrogenated, partially deuterated references were not available we used fully hydrogenated and fully deuterated model spectra. We started all refinements with the D:H anticipated from the multiple deuteration cycles, assuming that both isotopes leave the alanate proportional to concentration during desorption. However, we did not fix the ratio and allowed the refinement to optimize the fit and determine an H:D ratio for each spectrum (that is, each location and degree of desorption). Use of the multiple occupancy model along with the correct $\mathrm{Na}_{3} \mathrm{AlD}_{6}$ spectrum was essential to obtaining refinements that matched the data well.

The amount of sodium chloride at each location was expected to be roughly equal, and should be invariant on a mass basis. Clearly on a mole percent or relative mass basis the amount will vary due to the change in the total number of moles and total mass as desorption proceeds. The relatively constant amount of sodium chloride serves as an internal standard, providing a check on the reasonability of the fitted results. Graphite is also expected to be constant under these conditions (methane generation should be undetectable), however the $\mathrm{NaCl}$ peaks were less susceptible to interference from other compounds.

Not all the data was useable. Toward the closed end of the tube the signal became weak and noisy; these data were not well suited to fitting with 6 possible compounds. In the end, these data were dropped because the fit was insufficiently good to trust the resulting ratios of compounds. 
The same tube used in the primary data set was later used in the radiography and computed tomography experiments. These data were taken at the High Flux Isotope Reactor (HFIR). The use of the same tube allows a comparison of the chemical information from the diffraction data with the physical results from radiography. The tube was mounted horizontally and both rotated and translated to generate a tomographic mapping of the interior. Radiography was done only in the empty state. The spatial resolution is much higher in this work, with sub millimeter structures clearly distinguishable.

\section{Results:}

The radiography data are presented first to provide a better understanding of the condition of the alanate inside the unopened tube. Figure 10 shows radiography of the end of the tube near the valve, and neutron tomography of a cross-section. Clear inhomogeneities can be seen along the tube and across it. Areas of higher density and empty areas can be clearly seen. In radiography high neutron absorption or scattering is rendered in darker shades (high density metals and higher hydrogen content) while in the tomography darker shading indicates less material and lower absorption or scattering. These results confirm in-situ what was found from deconstructing another storage vessel from the same module. Photos of the valve end of the tube in Figure 11 show similar low density material and void areas. It is thought that the rapid flow of high pressure hydrogen into and out of the tube was the cause of this low density region.
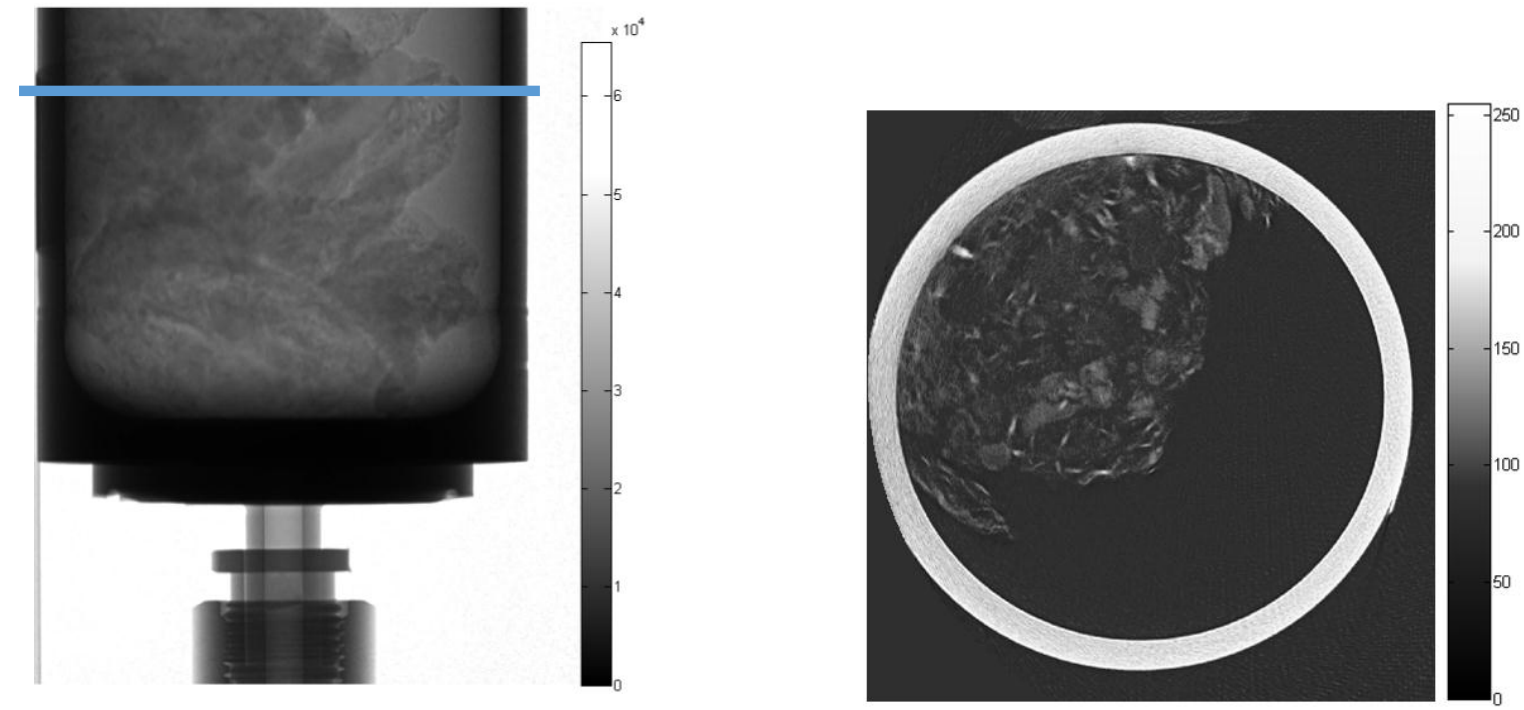

Figure 10: Neutron radiograph (left) and computed tomograph (right) of the hydrogen storage tube after the diffraction experiments were complete and the releasable hydrogen was desorbed. The blue bar at left shows the approximate position of the tomograph. The radiograph displays a transmission map. The white area outside of the sample is equivalent to $100 \%$ transmission or 65535 gray scale (16bit data). The cross-section slice shows an attenuation map where the dark areas inside the tube are indicative of $0 \%$ attenuation (i.e. voids). 


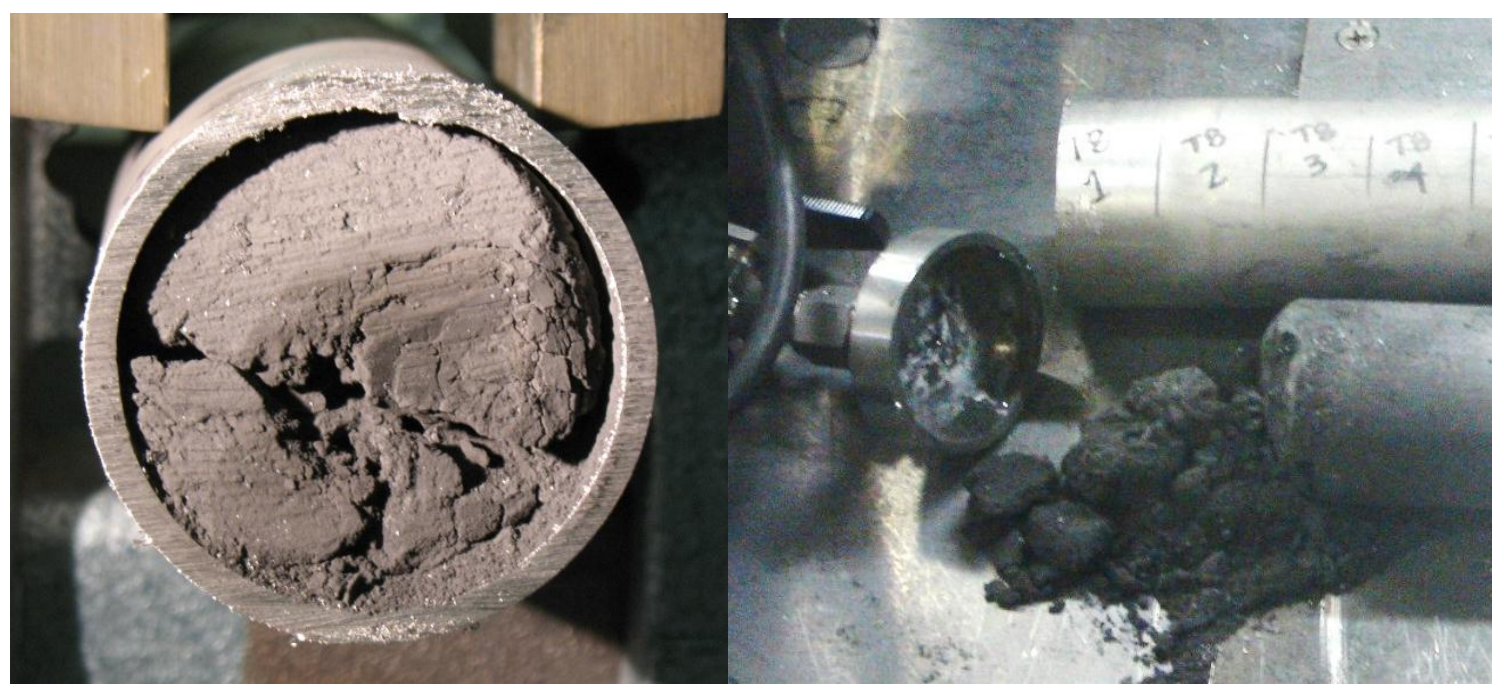

Figure 11: Close-up photos of a sectioned tube from Module 3 before and after the sodium alanate was removed.

As can be seen in the Figure 12, while empty portions of the tube are no longer seen at locations further along the tube, there are still variations in density and the appearance of cracks. Clearly, even though this tube has been cycled with hydrogen many times, the morpohology has not yet become isotropic.

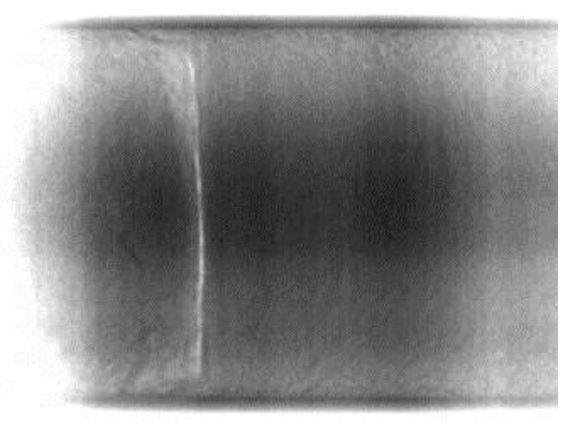

Figure 12: Neutron radiography at a position about $50 \mathrm{~mm}$ above the midline. A crack is clearly seen as a curved line to the left hand side of the figure.

Finally, as shown in Figure 13, radiography confirmed what had been predicted by modeling and found during tube sectioning; the presence of wall channeling. While difficult to see, the thin region near the tube wall that appears lighter than both the wall and the bulk material indicates a gap. Shown also in Figure 13 is a photo of the sectioned tube that shows a similar gap. 

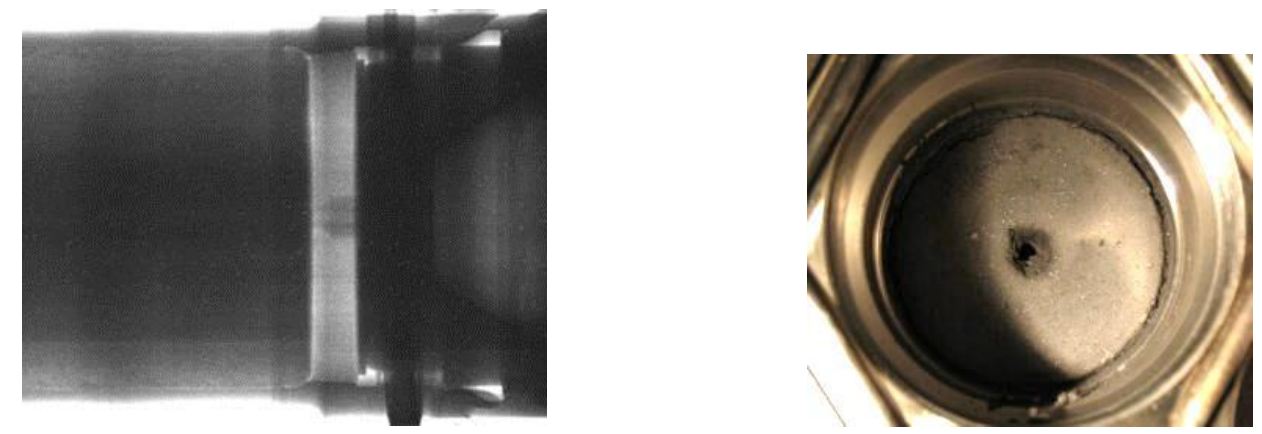

Figure 13: Neutron radiography at the closed end of the tube. A channel between the storage media and the steel wall can be seen in the radiograph as well as in the photo on the right.

Figure 14 shows the raw diffraction data as a function of wavelength and position after the tube had undergone the first ex-situ desorption. The data in this figure is not yet corrected for neutron flux as a function of wavelength. Aside from clear diffraction peaks it is evident that there is a decreasing background as a function of position. It is also important to consider specific diffraction lines for species that should be invariant with hydrogen content, such as the $\mathrm{NaCl}$ formed in the alanate creation process. Figure 15 shows the raw data for $\mathrm{NaCl}$. The intensity of this peak does show some noise, reflecting the variability introduced by the thick steel tube and the residual $\mathrm{H}^{1}$ in the sodium alanate, attenuating the neutron flux at the detector; but the signal does not vary significantly over the length of the tube.

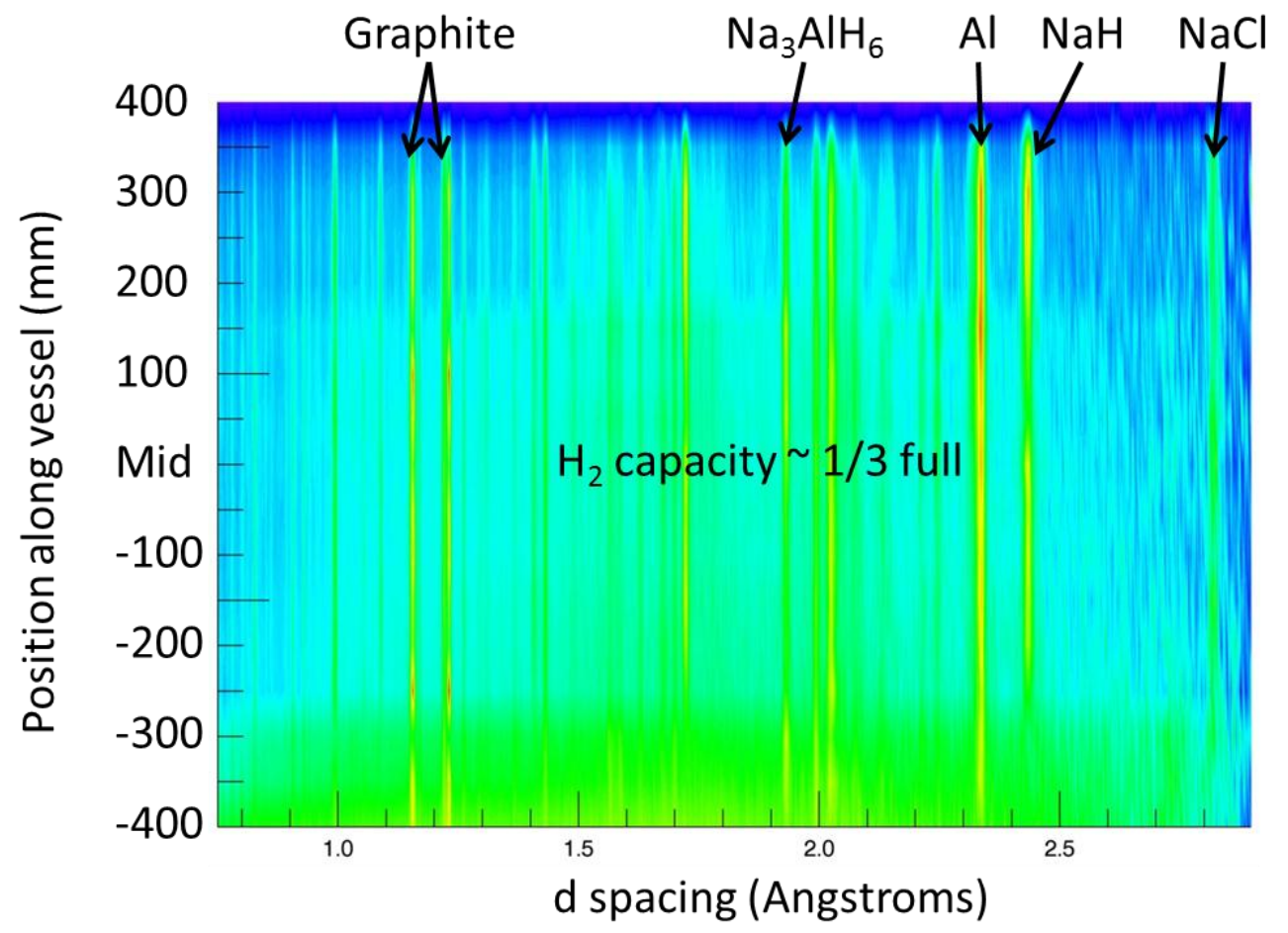

Figure 14: Neutron intensity at various positions as a function of D-spacing. A general decrease of background is seen moving from $-400 \mathrm{~mm}$ (closed end) to $400 \mathrm{~mm}$ (inlet) on the y axis. 


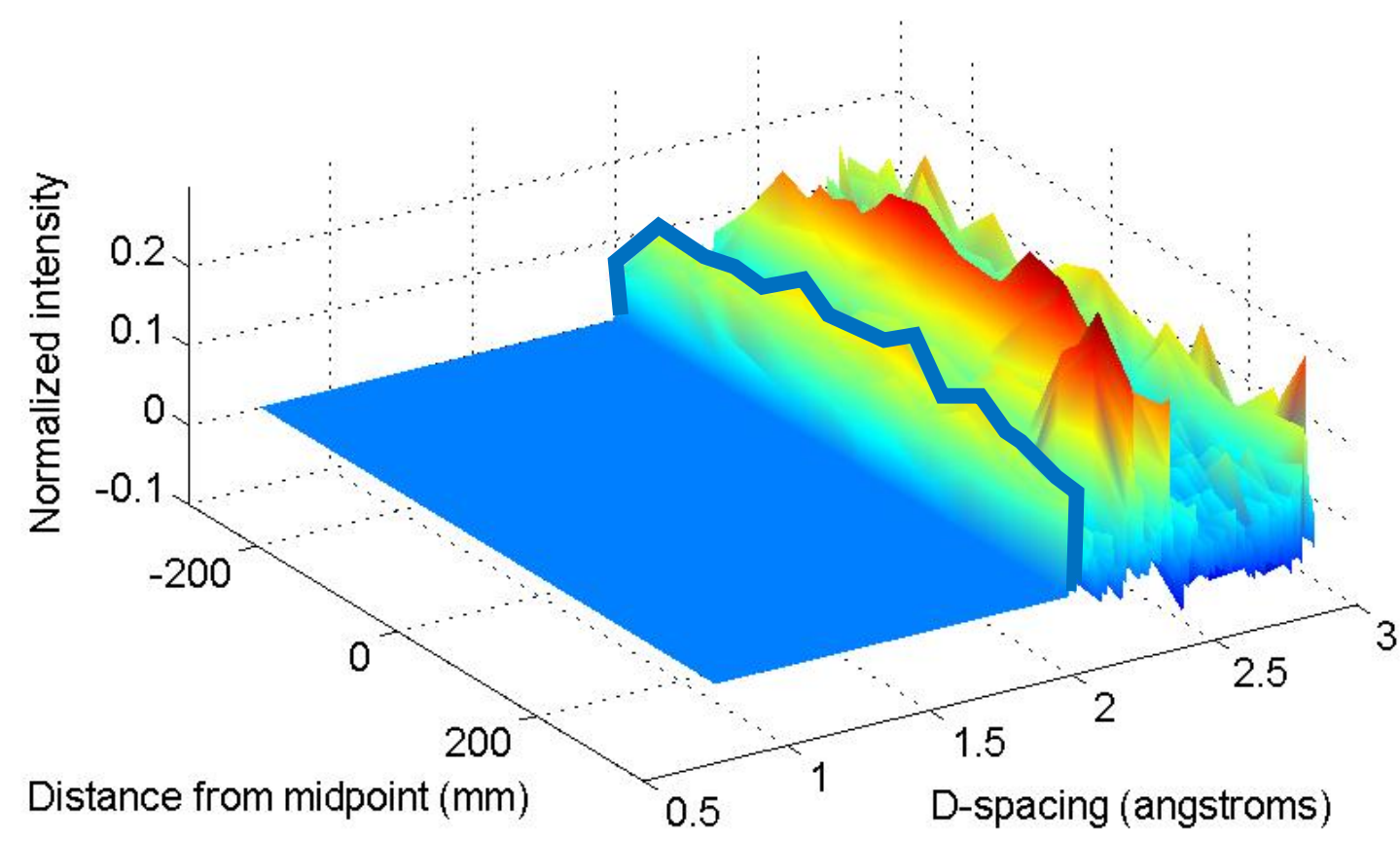

Figure 15: $\mathrm{NaCl}$ diffraction line as a function of position (blue line). There is not significant change in intensity with position.

The data were analyzed as described above to form maps of phase concentration vs. position along the length of the tube. Because it was not feasible to convert these working hydrogen storage tubes completely to deuterium, a mix of the two isotopes is present in all spectra. For brevity the following text will describe the various species as if only deuterium was present, but in fact a small amount of residual hydrogen is present as well. The $\mathrm{H}$ to $\mathrm{D}$ ratio will be analyzed in detail below.

In the initial work using three separate tubes from the same module we found little variation radially (see Figure 16). Since all the tubes were loaded slowly and desorbed slowly, it is logical that the heat transfer was adequate to ensure temperature gradients in the radial direction have little or no impact on the results reported here. Meaningful pressure gradients were not anticipated over the radial dimension. 


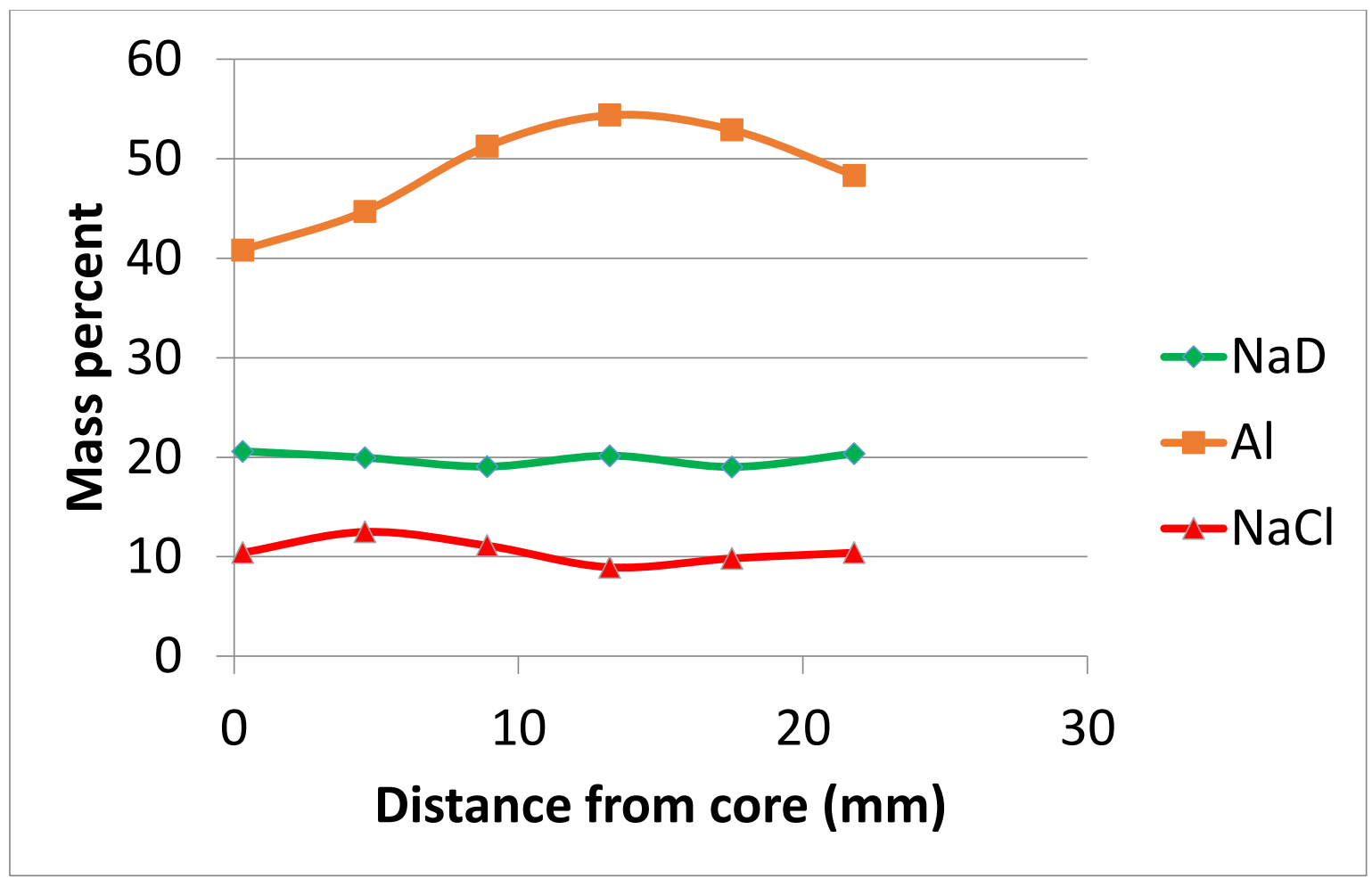

Figure 16: Radial variation in species at the midline of the tube.

Because we saw no radial variation in the initial work, in the subsequent primary desorption tests we chose to observe only a linear set of volumes near the shell of the tube and extending most of the complete filled length of the tube. In the largely full state, $\mathrm{NaAID}_{4}$ is clearly seen at all locations, but $\mathrm{Na}_{3} \mathrm{AlD}_{6}$ and free $\mathrm{Al}$ are also observed. The carbon and $\mathrm{NaCl}$ can also be clearly observed. The distribution of $\mathrm{NaCl}$ should be approximately constant and the carbon should also be independent of positional, though it is more likely that "clumps" of carbon might exist as it was only hand mixed, not mechanically milled. Figure 17 shows that indeed the $\mathrm{NaCl}$ concentration is relatively constant as is the carbon concentration. 


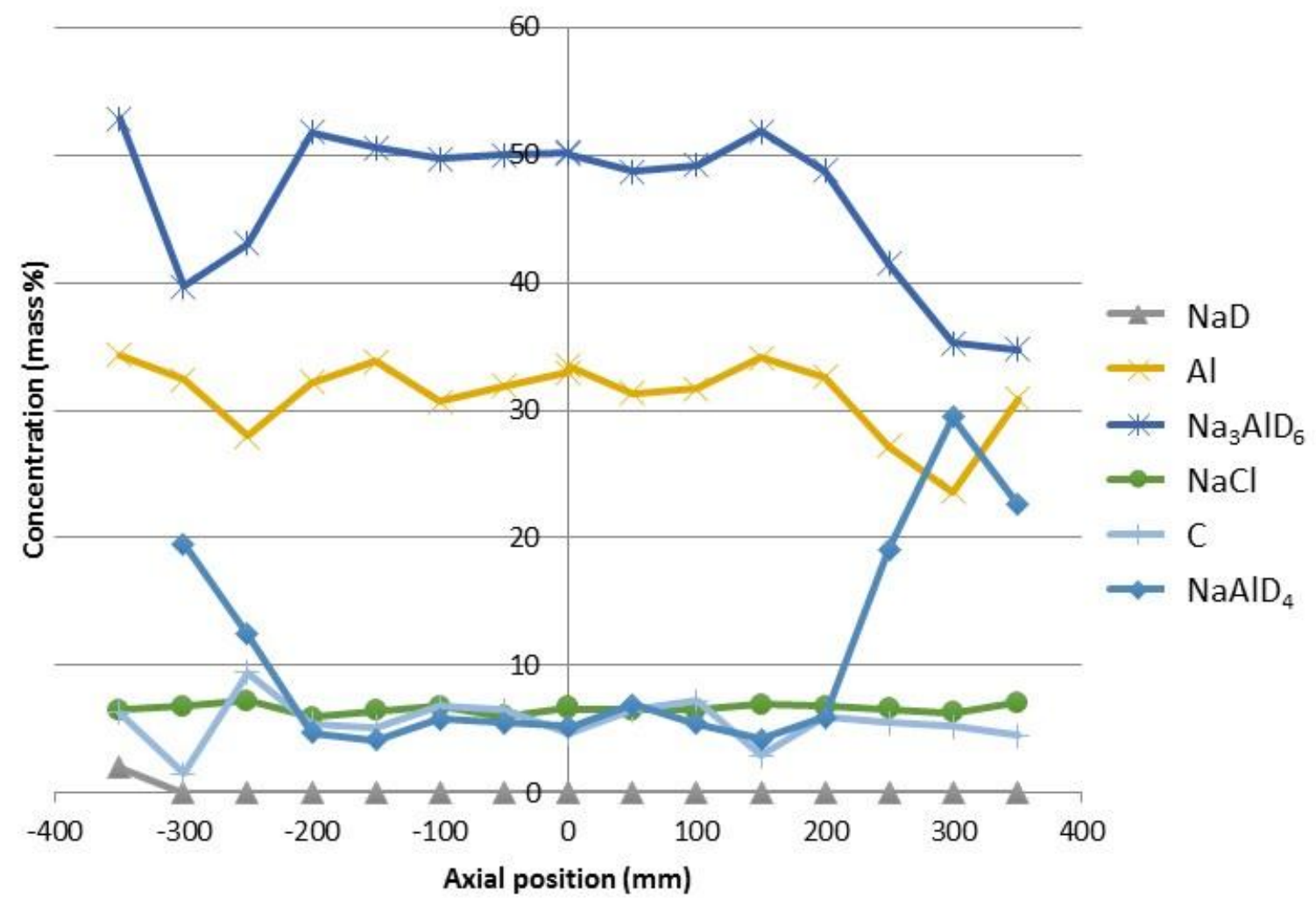

Figure 17. Concentration of the various components of the storage medium including phase resolution of the sodium alanate. The hydrogen content is roughly $2 / 3$ the capacity of the medium in this spectrum.

After removing 210 liters of hydrogen the tests were repeated in the same locations yielding the data in Figure 18. Clearly the $\mathrm{NaAlD}_{4}$ has all but disappeared and the $\mathrm{Na}_{3} \mathrm{AlD}_{6}$ phase has grown to dominate the spectrum along with the aluminum metal. Successive hydrogen removals lead to observation of $\mathrm{NaD}$, complete loss of $\mathrm{NaAlD}_{4}$, and a great reduction in $\mathrm{Na}_{3} \mathrm{AlD}_{6}$, see Figures 19 and 20 . 


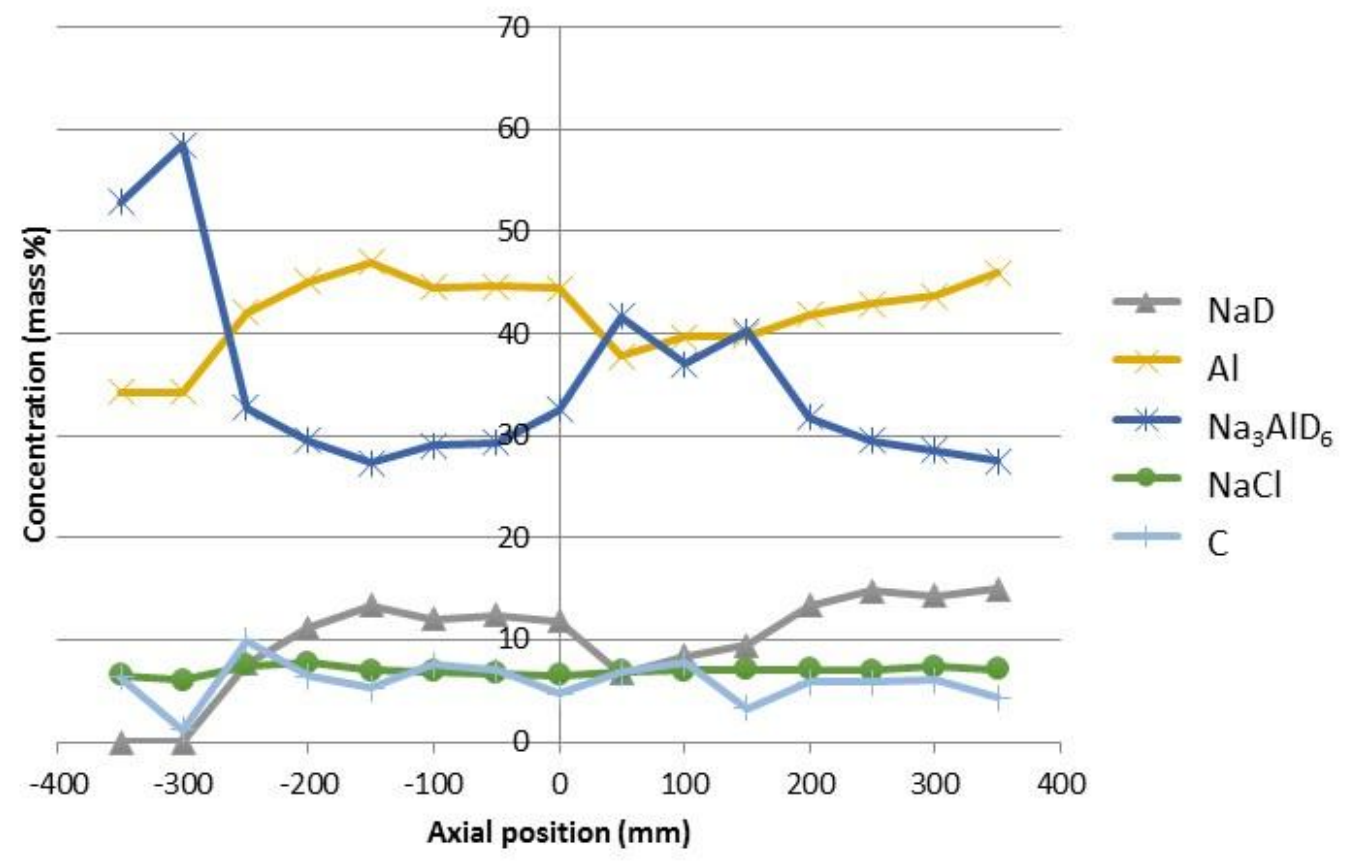

Figure 18. Concentration of the various components and sodium alanate phases after the first desorption. The medium is roughly at $50 \%$ capacity.

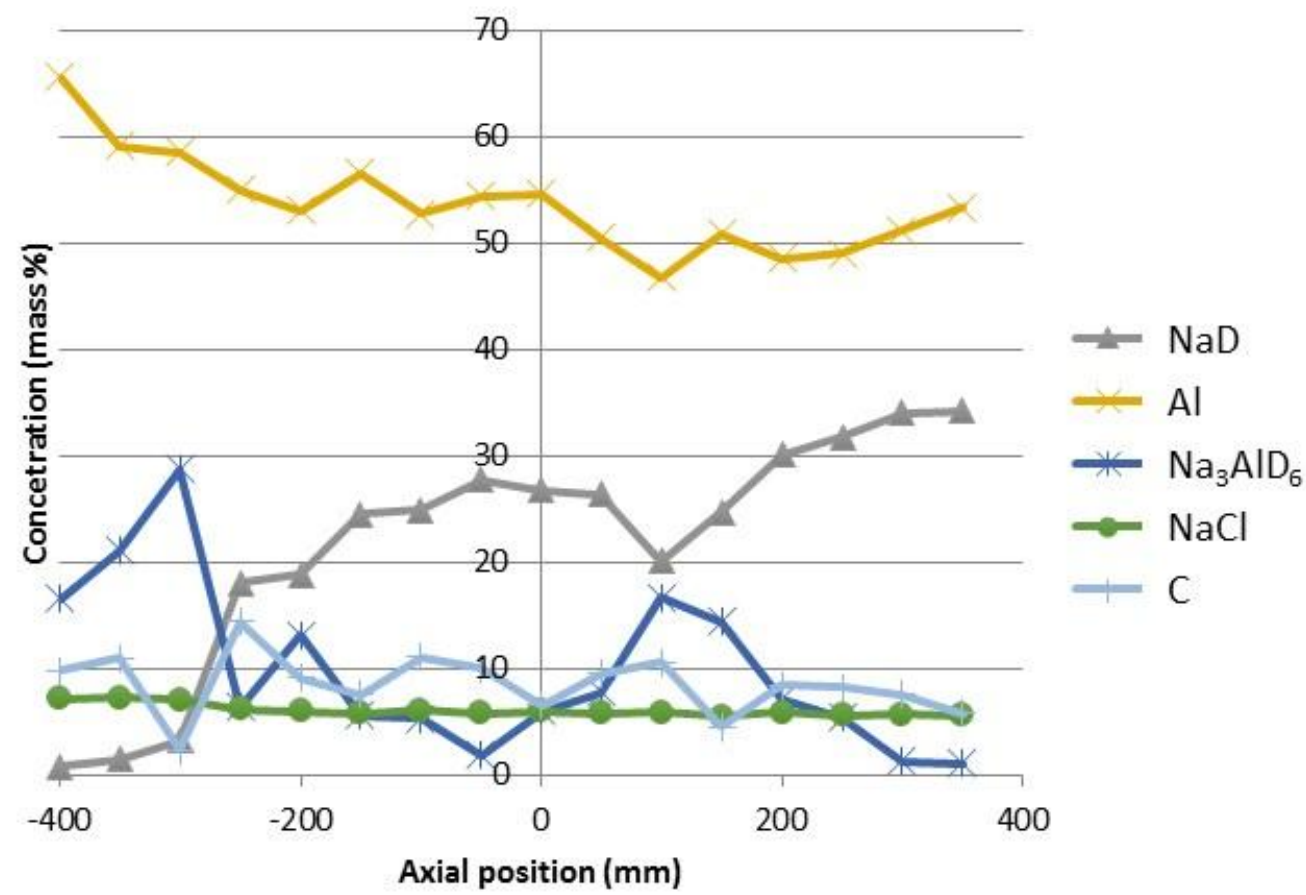

Figure 19. Concentration of the various components and sodium alanate phases after the second desorption. The medium is roughly at $\mathbf{2 5 \%}$ capacity. 


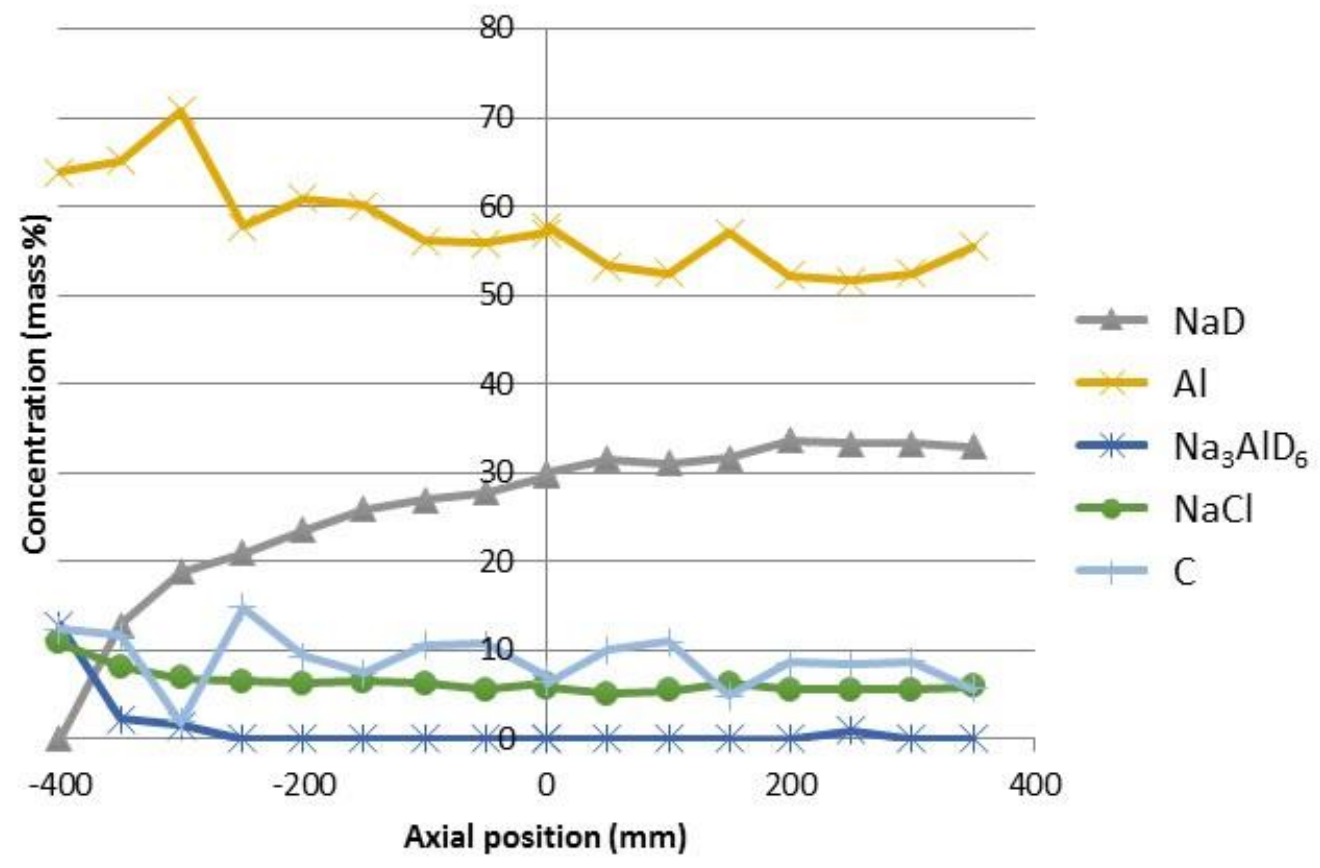

Figure 20. Concentration of the various components and sodium alanate phases after the final desorption. The medium is effectively exhausted of useable hydrogen.

As mentioned above, it was not feasible for us to fully convert nearly a kilogram of sodium alanate from its fully hydrogenated working form to the more convenient fully deuterated form. Because of the difference in scattering, it was important to analyze the neutron spectra allowing for the mixture of $\mathrm{H}$ and $\mathrm{D}$ atoms in the storage media. In Figure 21 the H/D ratio giving the best fit is shown at two levels of desorption, original, highest content state (a), and the half full state (b). In each case the $\mathrm{H} / \mathrm{D}$ ratio comes from the strong $\mathrm{Na}_{3} \mathrm{AlD}_{6}$ peaks. The ratio is very similar in both cases; the differences are likely to be simply due to the variance of the data. The slope however cannot be attributed to noise. 


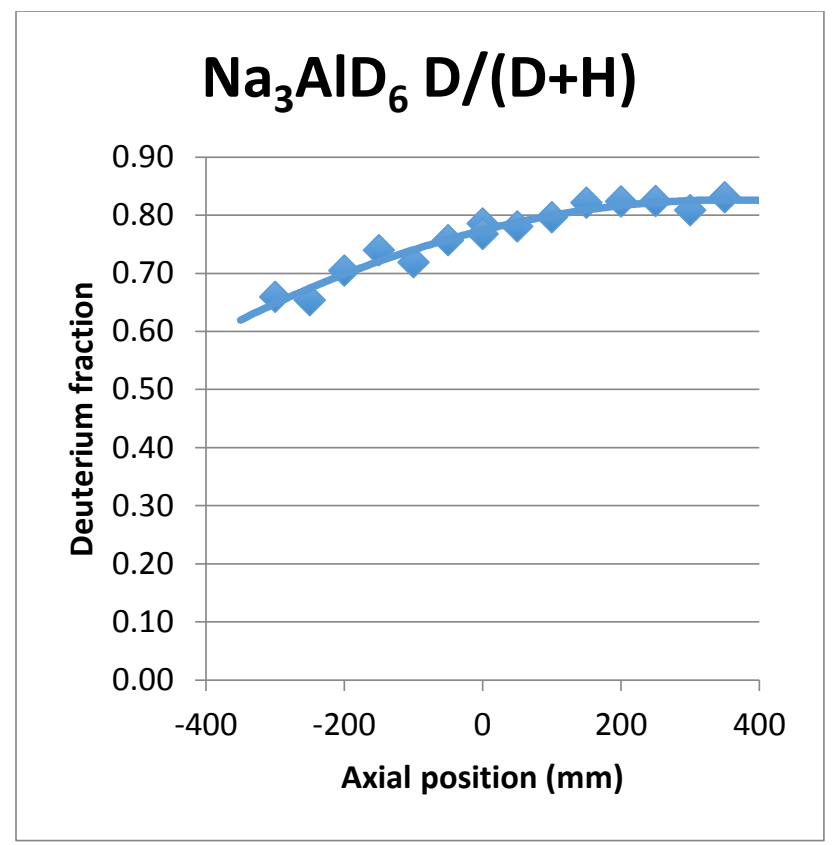

(a)

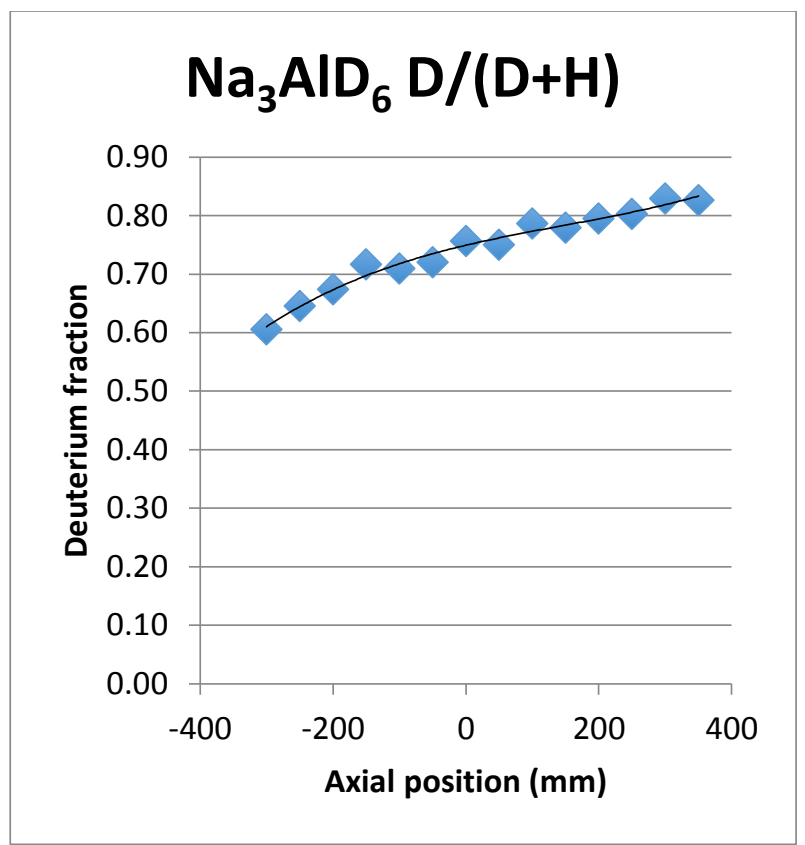

(b)

Figure 21 a \& b: Percent deuterium in $\mathrm{Na}_{3} \mathrm{AlD}_{6}$ as a function of position for the $\mathbf{5 0 \%}$ hydrogen content state (a) and the $33 \%$ full state (b).

\section{Discussion:}

As in the work of Bellosta von Colbe et al. [17] we see spacial non uniformity in bed. In that work a special visulization fixture was used. Here we confirm similar gaps and cracks in a well cycled sodium alanate bed in the full size tube. Figures 10,12 and 13 confirm in-situ the existance of avenues for increased flow of hydrogen. These types of features were anticipated in a generic sense when the models for flow did not match the results in testing of the full scale system [12]. Still, the tentative confimation provided by sectioning was important in that other explainations were conceivable. Nondestructive confirmation using radiography provides a high level of assurance that rapid axial movement of hydrogen along the wall followed by slower porous media flow to reach all the storage media can occur.

While wormholes along the length of the tube at the tube surface were not definitively seen they would be very hard to verify. Only a wormhole running circumfrentially would be simple to spot, presumably appearing as a small bubble like structure at the tube wall. In general the destructive inspection found the worm holes running roughly lengthwise where they would be harder to observe. The appearent absence of numerous large wormholes along the wall in the radiography may also indicate that this distinctive feature seen in the sectioned tube may not always be predominant. However the gap at the wall serves much the same flow function. On the other hand, confirmation of 
the radial cracks is a key finding, because it was impossible to eliminate the possibility that their appearance in the sectioned tube came from the mechanical stress of sectioning tube and removing the media. These cracks serve as a faster flow path to the core of the bed in the locations they are found, and further speed the flow of hydrogen to and from the bulk of the storage media. While the existance of some sort of structure to accelerate hydrogen transport was anticipated, non-destructive observation of the structures permits confident modeling of bimodal flow in future generations of this type of tank. In future, system design should account for the development of cracks, wall gaps and wormholes.

The general progression of phase changes in the sodium alanate over the course of desorption corresponds to what has been repeatedly shown with small samples (see amoung many others referrences 24-27 and references therein]. For example Figure 22, drawn from the data in figures 17-20 shows the $\mathrm{NaAlD}_{4}$ phase present in the loaded condition but absent in all 3 desobed spectra. This much is expected as the first desorption was designed to convert all NaAID 4 to $\mathrm{Na}_{3} \mathrm{AlD}_{6}$ without appreciably decomposing the product to $\mathrm{NaD}$. However, the highly nonlinear relation to position, dominated by two peaks for $\mathrm{NaAlH}_{4}$ at roughly $-300 \mathrm{~mm}$ and $+300 \mathrm{~mm}$ is not anticipated. The peak at the front end $(+250$ to +350 ) might be explained as simply the alanate absorbing gas along its length sequentially, filling the front half before the back half. But this explanation would imply a significant pressure gradient along the tube that is not anticipated and would be hard to explain in view of the wall gap. In addition, the peak at - $300 \mathrm{~mm}$ is not in accord with this explaination.

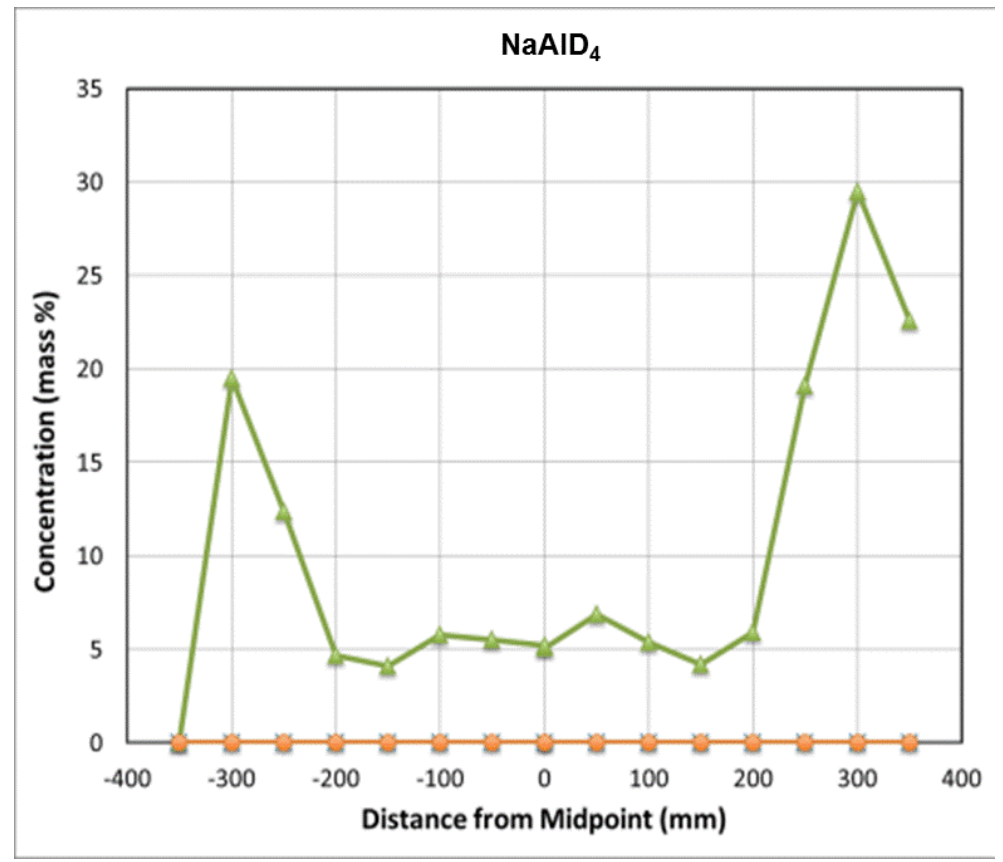

Figure 22. $\mathrm{NaAID}_{4}$ mass fraction along the length of the storage media for various amounts of desorption. The green triangles show the data at $50 \%$ fill. The $33 \%$ full, $10 \%$ full and the empty state fall on top of each other at 0 mass percent (e.g. the orange dimonds) .

One explaination is anisotropic flow along the tube. If the "wormholes" and cracks allow much faster flow and or higher pressure than occurs via movement through the media, then it is possible that 
certain areas will experience a greater pressure of hydrogen during absorption. In the core of dense volumes of the alanate, flow would be relatively restricted and the reaction to make $\mathrm{NaAlD}_{4}$ might consume deuterium faster than it could flow into the vicinity, thus lowering the pressure locally to the equilibrium value, leaving no driving force for further reaction with $\mathrm{Na}_{3} \mathrm{AID}_{6}$ until the slow flow rebuilds the pressure. Near a wormhole or crack the flow would be comparitively rapid and the pressure would not drop due to reaction, allowing a much greater extent of conversion.

The data for $\mathrm{Na}_{3} \mathrm{AlD}_{6}$ also has unexpected features. The data for the three desorptions are fairly consistent, with the $\mathrm{Na}_{3} \mathrm{AlD}_{6}$ content decreasing as deuterium is desorbed (Figure 23). However the initial state should have a lower $\mathrm{Na}_{3} \mathrm{AID}_{6}$ content since some of the $\mathrm{NaAID}_{4}$ remains unreacted and very little of the $\mathrm{Na}_{3} \mathrm{AlD}_{6}$ should have begun to convert to $\mathrm{NaD}$ at this temperature. Indeed, the $\mathrm{Na}_{3} \mathrm{AlD}_{6}$ curve at $\sim 50 \%$ state of fill is in fairly good agreement with the amount predicted at $33 \%$ state of fill, when $\mathrm{Na}_{3} \mathrm{AlD}_{6}$ content would be maximized. The higher mass fraction of $\mathrm{NaAlD}_{4}$ at $-300 \mathrm{~mm}$ previously seen in Figure 22 is seen inverted in the intial $\mathrm{Na}_{3} \mathrm{AlD}_{6}$ curve. At $+300 \mathrm{~mm}$ there is also a dip in the $\mathrm{Na}_{3} \mathrm{AlD}_{6}$ concentration where there is a peak in NaAID . In the partially desorbed states the $\mathrm{Na}_{3} \mathrm{AlD}_{6}$ is at its highest concentration at $-300 \mathrm{~mm}$.

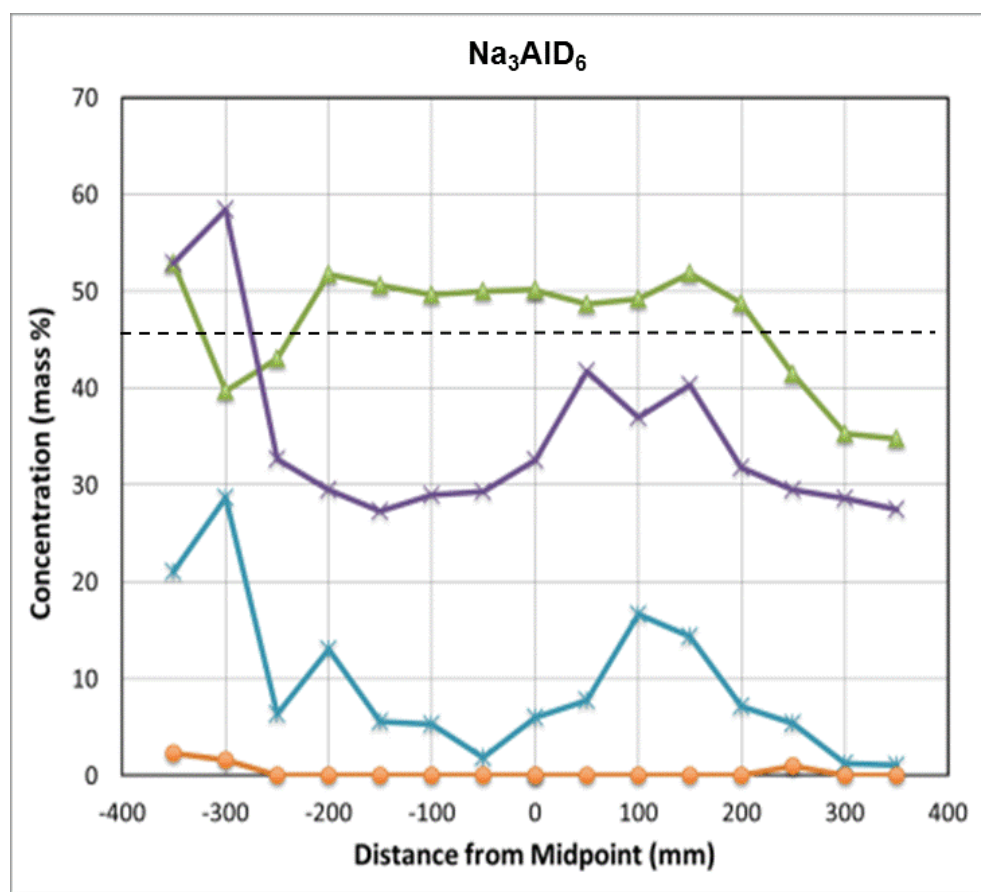

Figure 23. Mass fraction of $\mathrm{Na}_{3} \mathrm{AlD}_{6}$ at various desorption stages. The green triangles show the data at $\sim 50 \%$ fill, the purple $x$ at $33 \%$ full, blue asterix at $10 \%$ full and the orange circles at the empty state. The dashed line is the amount expected in the $33 \%$ full state based on the storage media formulation.

The relationship between the initial amounts of the two phases of sodium alanate are at least self consistent, with higher $\mathrm{NaAlD}_{4}$ concentration paired to lower $\mathrm{Na}_{3} \mathrm{AlD}_{6}$ concentration. This would imply unrestricted flow to the points at +300 and $-300 \mathrm{~mm}$. But unfortunately the data at $33 \%$ fill do 
not fully support this. The area at $-300 \mathrm{~mm}$ does increase in $\mathrm{Na}_{3} \mathrm{AlD}_{6}$ mass fraction as the $\mathrm{NaAID}_{4}$ disappears at the first desorption but the area at +300 does not, indeed it decreases further. Also unexplained by this concept is the shallow peak at about $+100 \mathrm{~mm}$.

Not all the $\mathrm{Na}_{3} \mathrm{AlD}_{6}$ is gone in the empty state, as would be expected. At the very end of the tube some $\mathrm{Na}_{3} \mathrm{AlD}_{6}$ remains even though it should have all been converted to $\mathrm{NaD}$ and $\mathrm{D}_{2}$. In tests on other tubes it was observed that hydrogen was evolved at temperatures well above those we accessed in these experiments, together these strongly suggest the small amount of $\mathrm{Na}_{3} \mathrm{AlD}_{6}$ remaining is real and represents stranded hydrogen.

Figure 24 shows the NaD mass fraction vs. postion at various stages of desorption. As expected there is no $\mathrm{NaD}$ to start the experiment and the amount grows in continuously. Also, there are valleys in the $\mathrm{NaD}$ curve at $-300 \mathrm{~mm}$ and $+100 \mathrm{~mm}$ where there are peaks in the $\mathrm{Na}_{3} \mathrm{AlD}_{6}$ curve, which is consistent. However, at $33 \%$ state of fill there should be no $\mathrm{NaD}$ formed and yet meanigful amounts are observed. Unexpectedly there is a general slope from the closed end to the inlet end which is not seen in the other phases and is not well explained. This effect grows with the increasing mass fraction of $\mathrm{NaD}$ in later desorptions. It should be noted that the amount of $\mathrm{NaD}$ is as predicted in the inlet half of the tube.

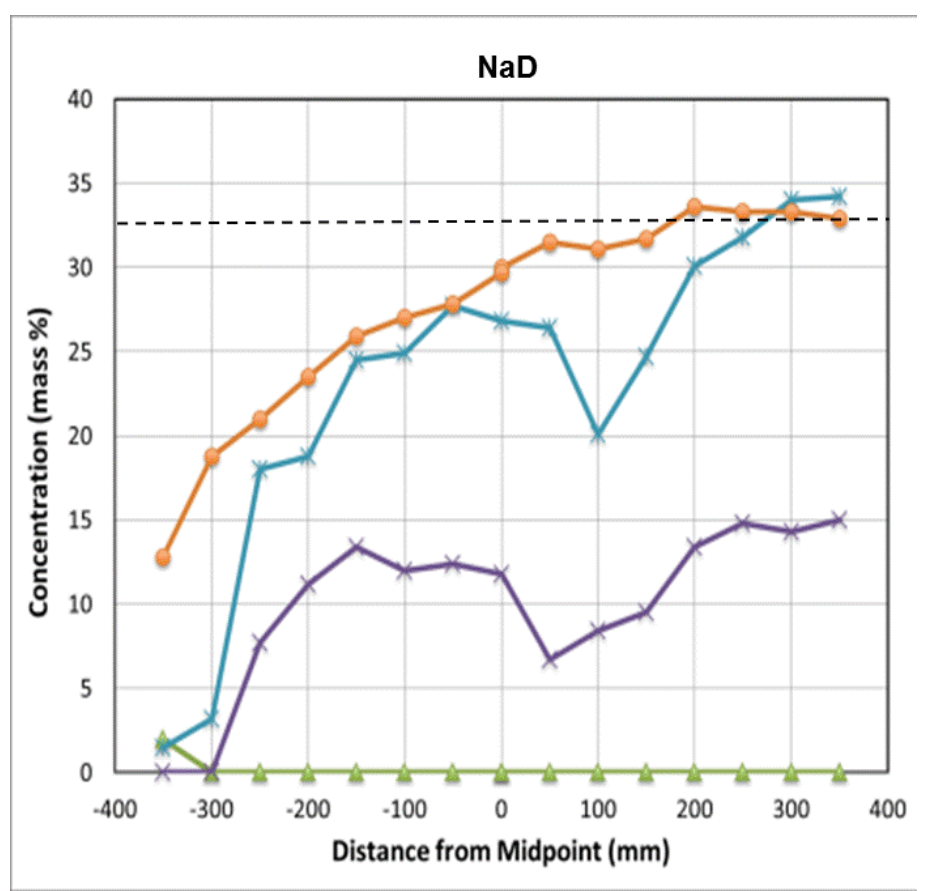

Figure 24. Mass fraction of $\mathrm{NaD}$ at various stages of desorption. The green triangles show the data at $\sim 50 \%$ fill, the purple $x$ at $33 \%$ full, blue asterix at $~ 10 \%$ full and the orange circles at the empty state. The dashed line is the amount expected in the empty state based on the storage media formulation.

Clearly the behaviour of a large sodium alante bed that has been repeatedly cycled is more complex than that of small samples. Figure 25 shows that the nonreactive species remain constant and 
near predicted values except perhaps for the empty state. This is important because it indicates the total mass balance is correct to first order. The observed drop in NaD corresponds primarily with a commensurate increase in $\mathrm{Al}$ (Figure 26), though graphite and $\mathrm{NaCl}$ do appear to generally increase slightly at the closed end of the tube.
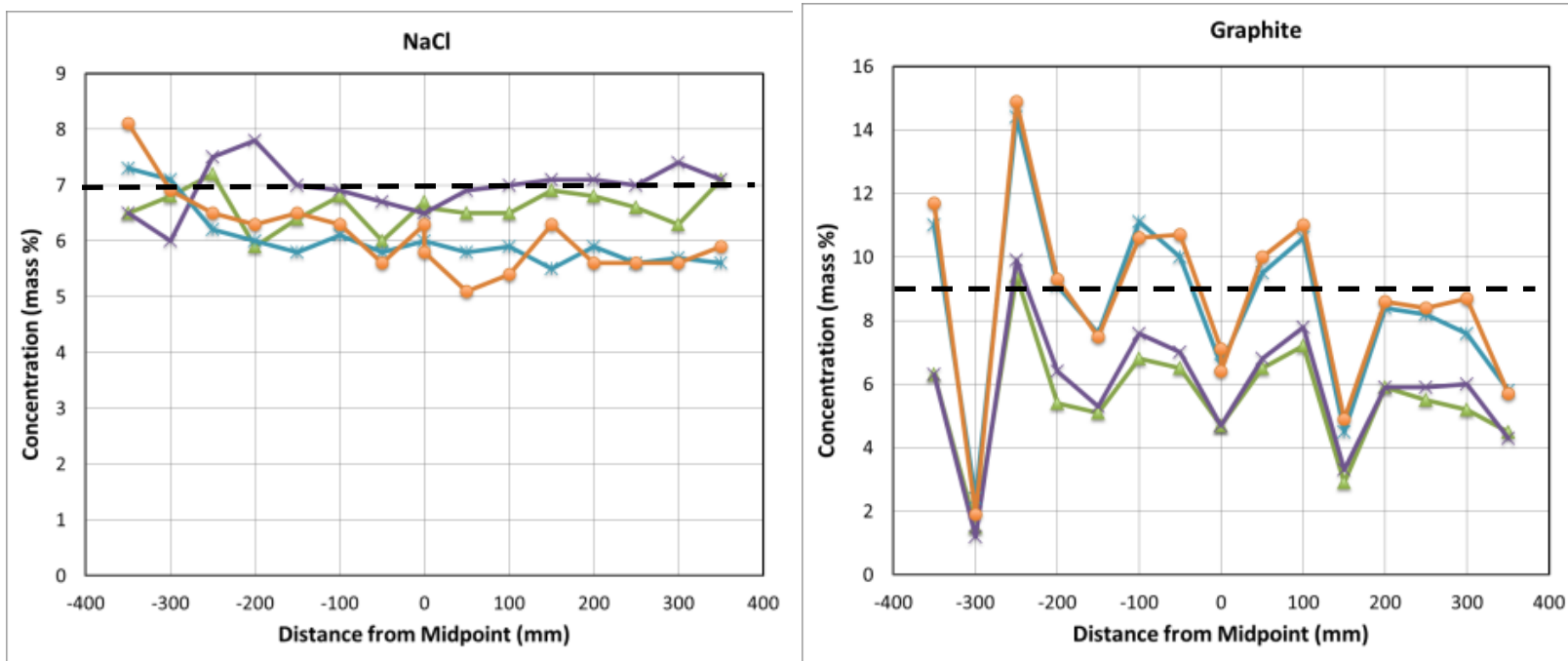

Figure 25. Mass fraction of $\mathrm{NaCl}$ and Graphite at various stages of desorption. The green triangles show the data at $50 \%$ fill, the purple $x$ at $33 \%$ full, blue asterix at $10 \%$ full and the orange circles at the empty state. The dashed line is the expected amount based on the storage media formulation.

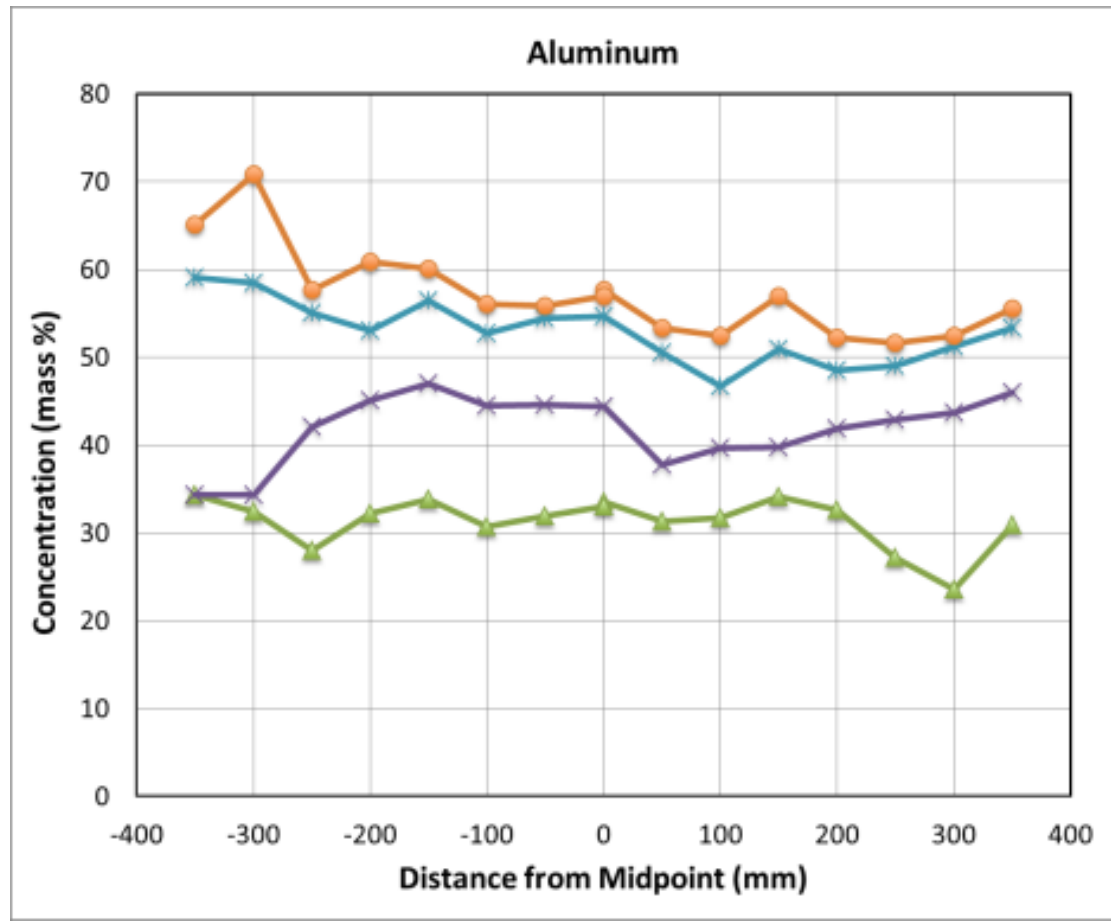

Figure 26. Mass fraction of Al at various stages of desorption. The green triangles show the data at $50 \%$ fill, the purple $x$ at $33 \%$ full, blue asterix at $\sim 10 \%$ full and the orange circles at the empty state. 
The $D /(H+D)$ ratio expected in the media is about $90 \%$, based on the amount of deuterium added and complete exchange between gaseous and bound hydrogen. The amount indicated by the best fit of the data in Figure 21 never excedes $85 \%$ and goes as low as $60 \%$ at the closed end of the tube. Neither the absolute level nor the slope with position was anticipated. Recall that the sample was initially completely hydrogenated and then repeatedly the sample was heated, the hydrogen pumped out, and redeuterated by an absorption step in pure deuterium. Because isotope exchange is slow at the tempretures of this experiment $[\mathbf{2 8}, \mathbf{2 9}]$, all that should have occurred is removal of hydrogen followed by replacement with deuterium in a separate absorption step. If any solid - gas isotope exchange occurred in addition to the expected absorption of deuterium to create the higher phases of alanate, the deuterium content would have been higher than expected. This did not happen, which is consistent with the references above.

Clearly there is increasingly poor removal of hydrogen (and thus absorption of deuterium) along the length of the alanate bed, but more than one explanation is possible. Ramirez-Cuesta reports that $D$ is preferentially absorbed into the alanates relative to $\mathrm{H}$, but also preferentially desorbs [30]. An explanation for this observation may be in the mechanism of hydrogen movement in alanates $[\mathbf{2 8}, \mathbf{2 9}]$. Ramirez-Cuesta also saw that in three cycles only a 1:1 $\mathrm{H}$ to $\mathrm{D}$ ratio is achieved when cycling between the $\mathrm{Na}_{3} \mathrm{AlH}_{6}$ and $\mathrm{NaAlH}_{4}$ phases [30]. It is possible this phenomenon might continue to the $\mathrm{NaH}$ phase which we used for deuteration, leaving a more $\mathrm{H}$ rich material than expected. This might also explain the weaker $\mathrm{NaD}$ signal at the closed end of the tube. Note that the $\mathrm{NaD}$ signal diminishes more or less in concert with decrease in $D /(H+D)$. Since it is possible to detect a species in diffraction only if there is order and the signal is intensified by longer range ordering, the "disappearance" of the NaD signal is consistent with the $\mathrm{NaH}-\mathrm{NaD}$ mixture ( $\mathrm{H}$ and $\mathrm{D}$ being mutually present) disrupting order enough to make the signal weaker. The mass balance would then favor other species, as observed. Because this slope is observed at all states of fill in the $\mathrm{NaD}$ data, and in the $\mathrm{D} /(\mathrm{H}+\mathrm{D})$ ratio of $\mathrm{Na}_{3} \mathrm{AlD}_{6}$ in the states of fill where the $\mathrm{Na}_{3} \mathrm{AlD}_{6}$ form is predominant, this state of disorder seems to persist through the desorption events.

Other possible explanations exist and they may have an effect on the data, but we feel they play a minor role relative to impact of $H$ and $D$ species disrupting long range order. It is possible that there is an actual mass transport limitation causing the observed effects, though this seems unlikely in part because the mechanism is unclear and also because the slope is fairly even indicating a uniform mechanism, not a blockage which would be expected to cause a step change. Another explaination is an anisotropic temperature distribution along the tube during the $\mathrm{H}$ desorption and $\mathrm{D}$ absorption steps. The desorption process was done in air and air currents conceivably could have kept the tube cooler on one end, lowering the amount of $\mathrm{H}_{2}$ evolved or $\mathrm{D}_{2}$ taken up. Finally there might be a distribution of the gas $\mathrm{H} / \mathrm{D}$ ratio in the gas flowing down the tube durring the $\mathrm{H}$ desorption and $\mathrm{D}$ absorption. During filling, any gas phase hydrogen evolved from the alanate due to displacement by deuterium would be pushed ahead of the incoming deuterium and would lower the $D_{2}$ concentration at the far end of the tube. In the desorption portion of the exchange process the various isotopic forms of hydrogen gas released would be also be able to exchange with the bed as it flowed out. However, for this mechanism to be valid the mass transfer through the gas phase must be very constrained so that a global 
equilibrium across the tube does not form later in the process while the temperature and pressure are held constant.

An alternative possibility is that despite efforts to maintain uniform conditions the tubes are not heated evenly in the desorptions that took place between neutron spectra. In these desorptions the ends were always slightly cooler. Peaks and valleys in the temperature profile durring the desorptions could also play a role. Furthermore, variation in the graphite concentration (Figure 25) will have altered the thermal conductivity of the bed slightly from one axial location to another; though there is no systematic variation in the axial direction. These sources of anisotropy in the heating experienced by any particular location in the tube might indeed acount for some of the unexpected peaks and valleys along the length of the tube, but not the over all structure. For example the peaks in the $\mathrm{Na}_{3} \mathrm{AlD}_{6}$ in Figure 23 may be in part due to variations in temperature reflecting the placement of the heat tape. However, we carefully wrapped the tape evenly and furthermore insulated the whole tube, so we believe variation in temperature should have had a small impact. While we do not expect the small temperature gradients mattered, it may be excacerbated in the interior of the bed due to heat transfer delays, especially in any location with slightly less graphite. However, the overall gradient in the H/D ratio (Figure 21) and the gradient in the hexahydride (Figure 23) do not reflect the variations in graphite content nor could heating tape placement account for them, these larger scale features must have another source.

In this work we have been able to observe the phase evolution as a function of hydrogen content in three dimentions, revealing some unexpected phenomina. Bollesta von Colbe and coworkers have demonstrated similar radiography results using in a special built visulization fixture that mimics the full tank [17]. Bowman et al. have also used neutron radiography to map hydrogen uptake in a metal hydride as a function of longitudinal position in a smaller system (though still full size for the space application intended)[15]. Using radiography and diffraction, virtually any hydrogen stroage bed could be mapped. It would be interesting to see the results for $\mathrm{LiBH}_{4}$ storage systems using neutron scattering to resolve the phases, or $\mathrm{MgH}_{2}$ in a full size bed using neutron absorption. After several types of storage have been tested, the function of a wide range of storage media could be compared after many cycles and in systems at vehicle scale. This would be very instructive because currently the bulk of our knowledge of hydrogen storage is limited to small samples that have undergone very limited cycling and only under the more controled conditions of lab testing. The proper engineering of storage systems needs to account for and if possible mitigate the effects of extended cycling. deRango et al. and Pourpoint et al. have built and cycled and modeled large Mg systems for hydrogen storage [31, 32]. In both groups significant effort was made to accommodate the anticipated degredation of the storage media. It would be very interesting to nondestructively measure how well those efforts succeeded as a function of bed position to facilitate further improvements.

Another key observation from an engineering standpoint is that hydrogen seems to be trapped in phases that should have decomposed. In addition, the H/D ratio was not uniform as would be expected, further indicating that $\mathrm{H}^{1}$ was 'stranded' or at least slow to desorb in parts of the tube during the deuteration process. While we could not pinpoint the precise mechanism in these neutron measurements, testing of samples destructively obtained from other tubes in the same module may offer a clue. Johnson and coworkers at Sandia found that in three alanate samples taken at roughly 
$25 \mathrm{~cm}, 50 \mathrm{~cm}$ and $75 \mathrm{~cm}$ from the inlet of a fully desorbed tube, there was evidence of the hexahydride phase remaining both from $x$-ray diffraction (XRD) measurements and thermogravimetric analysis.

Measurements using a Scintag XDS 2000 X-ray (powder) diffractometer were performed on samples from each region in the bed. Results are shown in Figure 27. Each of the samples downstream of the inlet showed clean diffraction patterns with minimal evidence of contamination. However, unlike at the inlet location, hexahydride is present in the regions away from the inlet of the tube. This would not be expected in a fully desorbed tube. In addition, peaks at the $50 \mathrm{~cm}$ and $75 \mathrm{~cm}$ locations were higher than at the $25 \mathrm{~cm}$ location indicating that the stranded hexahydride was more concentrated toward the end of the tube.

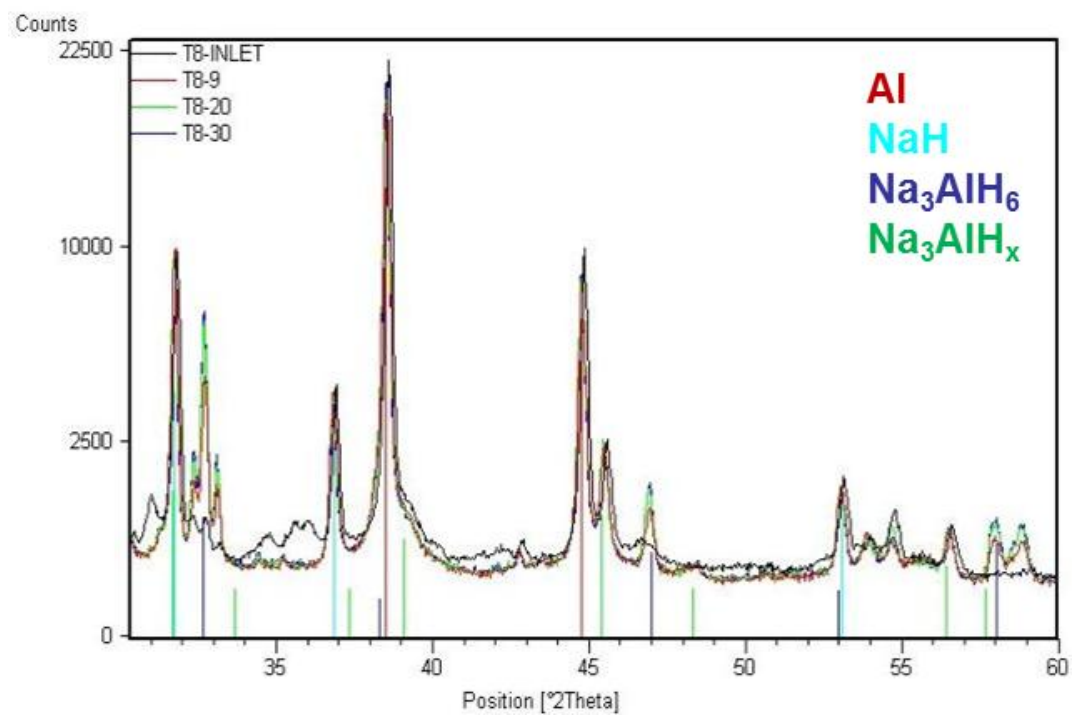

Figure 27. XRD powder diffractometry from four samples extracted from different points in a fully desorbed bed and tested ex-situ. Peaks at $2 \Theta=20$ and 54 indicate that increasing amounts of hexahydride were present at locations away from the tube inlet in a fully desorbed tube.

This phenomenon was further explored using thermogravimetric analyis with mass spectrometry. Measurements to quantify the evolution of gases from the samples during thermal decomposition were performed using the Simultaneous Thermogravimetric Modulated Beam Mass Spectrometer (STMBMS) at Sandia. The measurements involve heating a sample contained in a Knudsen cell under vacuum to produce a molecular beam that is characterized with a quadrupole mass spectrometer. Measured signals provide information on the quantity and the evolution rate of volatiles. Experiments were conducted on the sodium alanate samples taken from the same locations as the XRD samples. In each experiment the samples were heated from room temperature to $300^{\circ} \mathrm{C}$ at a rate of $2^{\circ} \mathrm{C} / \mathrm{min}$.

Figure 28 shows the hydrogen evolution rates as a function of temperature from the three tube locations compared to a reference sample of typical Ti-catalyzed $\mathrm{NaAlH}_{4}$. Note that the hydrogen evolution from the reference sample primarily occurs between 100 and $200{ }^{\circ} \mathrm{C}$ (Region 1), which is characteristic of hydrogen evolution from catalyzed tetrahydride $\left(\mathrm{NaAlH}_{4}\right)$ and hexahydride $\left(\mathrm{Na}_{3} \mathrm{AlH}_{6}\right)$. In comparison, the three samples showed hydrogen evolution between 200 and $280{ }^{\circ} \mathrm{C}$ (Region 2 ), which is 
characteristic of hydrogen evolution from uncatalyzed hexahydride. After this point, sodium begins to evolve from the sample due to the decomposition of the $\mathrm{NaH}$. The relative amount of $\mathrm{H}_{2}$ that evolves in each region changes as a function of location in the reactor bed. As the distance from the sample inlet increases, the amount of $\mathrm{H}_{2}$ evolved from Region 1 decreases and the amount of $\mathrm{H}_{2}$ from Region 2 increases. In the sample taken farthest from the inlet, the amount of $\mathrm{H}_{2}$ that evolves from the second region is greatest. This is in agreement with the XRD measurements that indicated the presence of residual hexahydride in the regions farthest from the tube inlet.

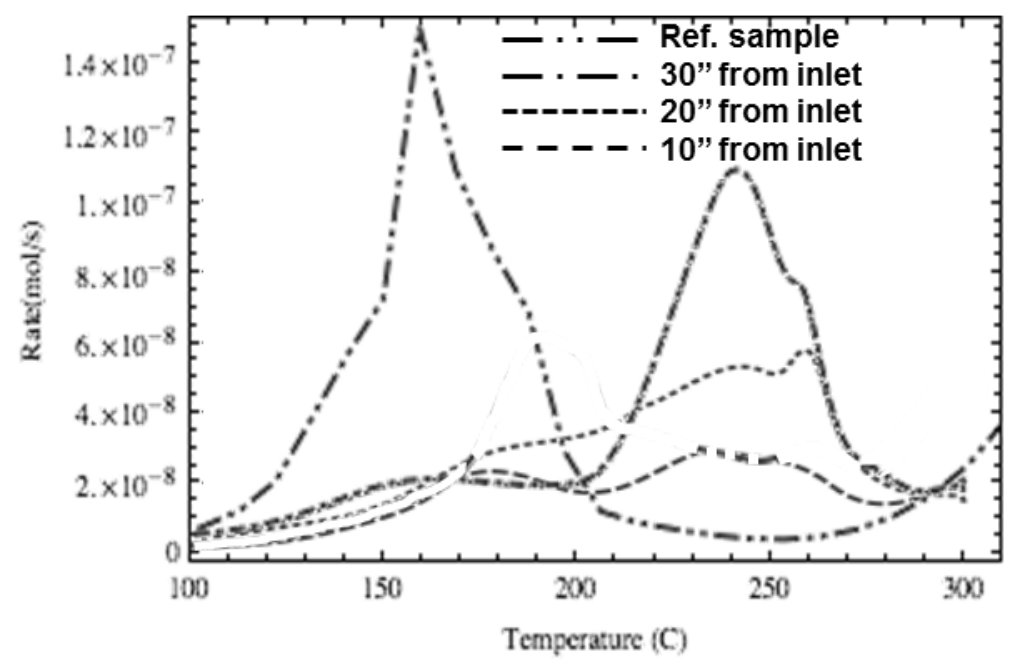

Figure 28. Comparison of the rate of evolution of $\mathrm{H} 2$ taken from three regions in the tube with a reference sample of Ti-catalyzed $\mathrm{NaAlH}_{4}$. Results indicate that residual uncatalyzed $\mathrm{Na}_{3} \mathrm{AlH} \mathrm{H}_{6}$ exists at the far end of the tube.

The XRD and especially the thermogravimetric analysis both seem to suggest a loss of catalyst function. The reason for reduced catalytic function is not fully clear; any of the mechnisms considered in the literature might be responsible $[\mathbf{2 7}, \mathbf{3 3}, \mathbf{3 4}]$; while the catalyst might be poisoned, it could also have simply segregated, or it is possible that the $\mathrm{NaH}$ and $\mathrm{Al}$, or $\mathrm{Na}_{3} \mathrm{AlH}_{6}$ and $\mathrm{Al}$ that form in the two dehydrogenation steps progressively become physically segregated to an extent that prevents effective rehydrogenation. This is a clearly important engineering consideration and the exact mechanism will be important to discriminate in order to improve the long term function of this type of storage tank. Only when we understand how real systems age can we truly begin to compare solid phase storage-systems for use in comercial applications.

\section{Conclusions:}

1. It is possible to resolve multiple phases of hydrogen storage media inside full scale storage beds, despite the attenuation due to the storage media, the presence of the steel jacket, and residual hydrogen.

2. After more than 70 simulated automotive cycles, the storage media is not morphologically isotropic along the length of the vessel. 
3. Hydrogen has alternate and less restricted travel paths via cracks and other free spaces, in addition to flow through the porous media of the bed. Any future tank design should include this phenomenon in the modeling and take advantage of the enhanced flow.

4. Conversion from $\mathrm{NaAlH}_{4}$ to $\mathrm{Na}_{3} \mathrm{AlH} \mathrm{H}_{6}$ to $\mathrm{NaH}$ was not uniform along the length of the tube.

5. Hydrogen-rich phases of sodium alanate persist in temperature and pressure conditions where desorption should occur, implying that locally the catalytic function of the added Ti can be severely degraded. This conclusion is further supported by the observed elevated desorption temperature for samples from those areas where an unexpected phase of sodium alanate is present. If these systems were to be used in the future, the precise cause of this loss of catalyst function must be determined and prevented.

6. Non-destructive analysis of the hydrogen content and the sodium alanate phase in which the hydrogen is absorbed can improve the modeling and engineering of full size, hydrogen storage in solid state media.

\section{Acknowledgments:}

We would like to acknowledge the help of many people who made these experiments possible. While not reported here, we conducted very valuable scoping studies using the WAND apparatus at HFIR, in addition to the radiography measurements. We are grateful to the operations and safety staff there who were so helpful in both these experiments; we would especially like to thank Jaime Fernandez-Baca, and Chris Redmon at HFIR for assistance in the radiography and in helping us do these studies that prepared us to work more effectively at SNS.

We also would like to thank the SNS management and staff, Xun-Li Wang, Ke An, Ducu Stoica, and especially Ling Yang, and Harley Skorpenske. We also thank the safety staff at SNS, for their conscientious and timely review of our somewhat unusual experiment.

All the alanate tubes were created at Sandia National Laboratory under a joint project between General Motors Research and Development and Sandia. We are grateful to Daniel Dedrick, Mike Knauff, George Sartor and Rich Behrens who assisted in the system design, assembly and testing and the preparation of the tubes at Sandia.

We wish to thank the GM hydrogen program that funded the development of the alanate based storage system and for supporting the program as a whole.

A portion of this research at ORNL's High Flux Isotope Reactor and Spallation Neutron Source, was sponsored by the Scientific User Facilities Division, Office of Basic Energy Sciences, US Department of Energy, and by the Assistant Secretary for Energy Efficiency and Renewable Energy, Office of Vehicle Technologies, as part of the HTML User Program, Oak Ridge National Laboratory. Sandia National Laboratories is a multi-program laboratory managed and operated by Sandia Corporation, a wholly owned subsidiary of Lockheed Martin Corporation, for the U.S. Department of Energy's National Nuclear Security Administration under contract DE-AC04-94AL85000. 


\section{References:}

[1] "International Energy Outlook 2010". U.S. Energy Information Administration, US Department of Energy, DOE/EIA-0484(2010), 2010.

[2] International Energy Outlook 2014, U.S. Energy Information Administration, Sept., 2014. DOE/EIA0484(2014).

[3] Sun Y, Ogden J, Delucchi M. (2010) Societal Lifetime Cost of Hydrogen Fuel Cell Vehicles. Institute of Transportation Studies, University of California, Davis, Research Report UCD-ITS-RR-10-09.

[4] 2014 Annual progress report, DOE hydrogen and fuel cells program, Nov. 2014 DOE/GO-1020144504.

[5] Pasini J, Corgnale C, van Hasse B, Motyka T, Kumar S, Simmons K, Metal hydride material requirements for automotive hydrogen storage systems. Int. J. Hydrogen Energy 2013; 38: pp. 9755-65.

[6] Eberle U, Felderhoff M, Schuth F. Chemical and physical solutions for hydrogen storage. Ang Chem 2008; 48: pp. 6608-30.

[7] McWhorter S, Read C, Ordaz G, Stetson N, Materials-based hydrogen storage: Attributes for nearterm, early market PEM fuel cells. Current Opinion in Solid State and Materials Science 2011; 15: pp 2938.

[8] Jorgensen S, Hydrogen Storage Tanks for Vehicles: Recent Progress and Current Status. Cur. Op. in Solid State Mat. Sci. 2011; 15: pp. 39-43.

[9] V. Strubel, Hydrogen Storage Systems for Automotive Application, StorHy Final Activity Report, Oct $15,2008$.

[10] AK Steel, Specialty Stainless Sheet \& Strip Stainless Price Schedule. AK Steel, http://www.aksteel.com/pdf/markets_products/stainless/stainlesssteelpricelist.pdf, August 2012

[11] Johnson T, Jorgensen S, Dedrick D. Performance of a Full-Scale Hydrogen-Storage Tank Based on Complex Hydrides. Faraday Discussions 2011; 151: p 327-52.

[12] Johnson T, Kanouff M, Dedrick D, Evans G, Jorgensen S. Model based design of an automotivescale, metal hydride hydrogen storage system. Int J Hydrogen Energy 2012; 37(3): p2835-49.

[13] Sakaguchi H, Kohzai A, Hatakeyama K, Fujine S, Yoneda K, Kanda K, Esaka T. Visualization of hydrogen in hydrogen storage alloys using neutron radiography. Int J Hydrogen Energy 2000; 25: pp. 1205-8.

[14] Sakaguchi H, Satake Y, Hatakeyama K, Fujine S, Yoneda K, Matsubayashi M, Esaka T. Analysis of hydrogen distribution in hydrogen storage alloy using neutron radiography. J Alloys Comp. 2003; 354: pp. 208-15. 
[15] Jacobson D, Hussey D, Baltic E, Udovic T, Rush J, Bowman R, Neutron imaging studies of metalhydride storage beds, Int J Hydrogen Energy 2010; 35(23): pp. 12837-45.

[16] Pranzas P K, et al., Characterization of Hydrogen Storage Materials and Systems with Photons and Neutrons, Adv. Eng. Materials 2011; 13(8): pp. 730-6.

[17] Bellosta von Colbe $\mathrm{J} \mathrm{M}$, et al., Behavior of scaled-up sodium alanate hydrogen storage tanks during sorption, Int J Hydrogen Energy 2011; doi:10.1016/j.jhydene.2011.03.153.

[18] B. Bogdanovic, M.J. Schwickardi, J. Alloys Comp. 1997; 253: pp 1-9.

[19] G. Sandrock, K. Gross, G. Thomas, C. Jensen, D. Meeker, S. Takara, Engineering considerations in the use of catalyzed sodium alanates for hydrogen storage, J. Alloy and Comp. 2002; 330-332: pp 696701.

[20] G. Majer, et al., Effects of catalysts on the dehydriding of alanates monitored by proton NMR, J.Alloys Compounds 2005; 404-406: pp 738-42.

[21] E. G. Sorte, et al., Mobile species in NaAlH4, J. Phys. Chem. C 2013; 117: pp8105-13.

[22] Dedrick D, Kanouff $P$, Larson R, Johnson T and Jorgensen $S$. Heat and Mass Transport in Metal Hydride Based Hydrogen Storage Systems. Proceedings of the ASME 2009 Heat Transfer Summer Conference 2010; pp. 249-60;

[23] B. H. Toby, EXPGUI, a graphical user interface for GSAS, J. Appl. Cryst 2001; 34: pp210-13.

[24] R.A. Zidan, S. Takara, A.G. Hee, C.M. Jensen: J. Alloys Compd. 285, 119 (1999)

[25] B. Bogdanovic, R.A. Brand, A. Marjanovic, M. Schwickardi, J. Tölle: J. Alloys Compd. 302, 36 (2000)

[26] C.M. Jensen, K.J. Gross, Development of catalytically enhanced sodium aluminum hydride as a hydrogen-storage material, Appl. Phys. A 2001; 72: pp 213-19.

[27] B. Sakintuna, F. Lamari-Darkrimb, M. Hirscher, Metal hydride materials for solid hydrogen storage: A review, Int. J. Hyd. Energy 2007; 32: pp $1121-40$.

[28] A. Borgschulte, et al., "Hydrogen-deuterium exchange experiments to probe the decomposition reaction of sodium alanate", Phys. Chem. Chem. Phys. 10 (2008) 4045-55.

[29] A. Borgschulte, et al., "Hydrogen diffusion in $\mathrm{NaH}$ as derived from isotope exchange experiments", Appl. Phys. Lett. 94 (2009) 111907.

[30] Ramirez-Cuesta, A. Personal communication, unpublished. 2013.

[31] Chaise, A, de Rango, P, Marty, P, Fruchart, D. Experimental and numerical study of a magnesium hydride tank. Int J Hydrogen Energy 2010; 35: 6311-22.

[32] Visaria, M, Mudawar, I, Pourpoint, T, Kumar, S. Study of Heat Transfer and Kinetics Parameters Influencing the Design of Heat Exchangers for Hydrogen Storage in High-Pressure Metal Hydrides. Int $\mathrm{J}$ of Heat and Mass Transfer 2010; 53(9-10): 2229-39.

[33] A.G. Haiduc, H.A. Stil, M.A. Schwarz, P. Paulus, J.J.C. Geerlings, On the fate of the Ti catalyst during hydrogen cycling of sodium alanate, J Alloy and Comp. 2005; 393: pp 252-63 
[34] Bogdanovic B, Felderhoff M, Kaskel S, Pommerin A, Sclichte K, Schüth F. Improved hydrogen storage properties of Ti-doped sodium alanate using titanium nanoparticles as doping agents, Adv Mater 2003; 15(12): pp1012-15. 